\title{
Megavolt Bremsstrahlung Measurements from Linear Induction Accelerators Demonstrate Possible Use as a FLASH Radiotherapy Source to Reduce Acute Toxicity
}

\section{Stephen Sampayan ( $\sim$ sampayan1@llnl.gov )}

Lawrence Livermore National Laboratory

\section{Kristin Sampayan}

Opcondys, Inc. 600 Commerce Court

\section{George Caporaso}

Lawrence Livermore National Laboratory

\section{Yu-Jiuan Chen}

Lawrence Livermore National Laboratory

\section{Steve Falabella}

Lawrence Livermore National Laboratory

\section{Steven A. Hawkins}

Lawrence Livermore National Laboratory

Jason Hearn

University of Michigan

James Watson

Lawrence Livermore National Laboratory

Jan-Mark Zentler

Lawrence Livermore National Laboratory

\section{Research Article}

Keywords: FLASH radiotherapy, linear induction accelerator, toxicity

Posted Date: April 28th, 2021

DOI: https://doi.org/10.21203/rs.3.rs-472437/v1

License: () (1) This work is licensed under a Creative Commons Attribution 4.0 International License.

Read Full License 
Version of Record: A version of this preprint was published at Scientific Reports on August 24th, 2021. See the published version at https://doi.org/10.1038/s41598-021-95807-9. 


\title{
Megavolt Bremsstrahlung Measurements from Linear Induction Accelerators Demonstrate Possible Use as a FLASH Radiotherapy Source to Reduce Acute Toxicity
}

\author{
Stephen E. Sampayan ${ }^{a, b^{*}}$, Kristin C. Sampayan ${ }^{b}$, George J. Caporaso $^{a}$, \\ Yu-Jiuan Chen ${ }^{a}$, Steve Falabella a, Steven A. Hawkins ${ }^{a}$, Jason Hearn ${ }^{c}$, \\ James A. Watson ${ }^{a}$, and Jan-Mark Zentler ${ }^{\mathrm{a}}$
}

a Lawrence Livermore National Laboratory, P.O. Box 808, Livermore, CA 94551, USA

*Corresponding author e-mail address: sampayan1@IInl.gov

${ }^{b}$ Opcondys, Inc. 600 Commerce Court, Manteca, CA 95336, USA

c Department of Radiation Oncology, University of Michigan, Ann Arbor, MI 48109, USA 
1

2

3

4

5

6

$7 \mathrm{~s}^{-1}$ with a maximal effect at $>100 \mathrm{~Gy}-\mathrm{s}^{-1}$ that must be maintained in the treatment volume.

8 Mechanisms are still widely debated, but toxicity is minimized while inducing apoptosis in

9 malignant tissue. Delivery technologies to date show that a capability gap exists with clinic scale,

10 broad area, deep penetrating, high dose rate capability. Based on present trends, if FLASH-RT is

11 adopted, it may become a dominant approach except in the least technologically advanced

12 countries. The linear induction accelerator (LIA) developed for high current, high repetition rate,

13 species independent charged particle acceleration, has yet to be considered for this application.

14 We briefly review the status of LIA technology, explore the physics of bremsstrahlung-converter-

15 target interactions and our work on stabilizing the electron beam. While the gradient of the LIA

16 is low, we present our preliminary work to improve the gradient by an order of magnitude,

17 presenting a point design for a multibeam FLASH-RT system using a single accelerator for 18 application to conformal FLASH-RT.

19

20 Introduction

21

22 treatment (FLASH-RT). This technique delivers a prompt high radiation dose, sometimes in a

23 single treatment rather than spacing the dose over a longer period of time [ 123 ]. While the 
1 healthy tissue sparing effect associated with FLASH-RT has a threshold of $40 \mathrm{~Gy}-\mathrm{s}^{-1}$, a maximal

2 effect occurs at $>100 \mathrm{~Gy}-\mathrm{s}^{-1}$, with some techniques using instantaneous dose rates as high as

$310^{8} \mathrm{~Gy}^{-1} \mathrm{~s}^{-1}$ in a single 23-MeV, $1 \mathrm{~ns}$, proton pulse [ 456 7]. Hypothesized mechanisms include

4 oxygen depletion or a modified immune response.

$5 \quad$ Human trials are still very limited with one report of 167 Gy-s-1 (15-Gy in 90-ms)

6 delivered for treatment of a 3.5-cm diameter skin tumor (Fig. 1). This treatment used electrons

7 from an Oriatron eRT6 5.6 MeV microwave LINAC at the Lausanne University Hospital [ 8 9].

8 Although it was not possible to draw any firm conclusions, the trial demonstrated treatment

9 was feasible and safe and showed a favorable outcome for normal skin. Tumor response

10 appeared rapid and complete.

Pulsed power accelerators store energy over a comparatively long time and are

12 discharged in 10 s to 100 s of nanoseconds to deliver pulsed high-power beams. While

13 anecdotal, one of the authors is aware of three separate accounts of the same accidental FLASH

14 dose event that occurred in the mid-1960s. A single pulse, 7-8 MeV, 50 ns pulsed power FLASH

15 electron accelerator accidentally fired while an individual was in the radiation vault. At least

16 one account purports the individual observed a "blue flash" consistent with the recent single

17 human trial [ 8]. The individual received near the $\mathrm{LD}_{50}$ bremsstrahlung dose with little, if any,

18 clinical effect [ 10]. Soon afterwards, this same type of pulsed power accelerator was used in

19 some of the original FLASH radiation effect studies on mammalian tissue. That research served

20 as the basis for the work today[ 11]. 
Although some believe FLASH-RT holds great promise and is perhaps the biggest development in recent radiotherapy history, some remain skeptical about the replication of efficacy and have concerns about technical complexity, the lack of understanding of its

4 molecular radiobiological underpinnings, and reliability [ 12]. Clearly, significant work remains

5 to be done.

A survey of FLASH-RT delivery systems is shown in Figure 2 with added details provided

7 in Table I. We clearly show the need for clinic scale multi-MV FLASH-RT systems. Here we plot

8 the dose rate as a function of range (in terms of $R=\rho d x$ ) for electrons, photons, and protons [ 3

9791314151617181920212223 24]. We make a distinction between clinic scale systems

10 that would fit in a nominal treatment vault of about $100 \mathrm{~m}^{3}$ (solid blue filled markers) from

11 more costly research centers as well as specialized high energy proton facilities (open markers).

12 Each of these facilities provides a nominal FLASH-RT area ranging from $7.5 \times 10^{-5} \mathrm{~cm}^{2}$ at a range

13 of about $1.3 \mathrm{gm}-\mathrm{cm}^{-2}$ for $20 \mathrm{MeV}$ protons to the largest area of $55 \mathrm{~cm}^{2}$ at a range of about $3 \mathrm{gm}$ -

$14 \mathrm{~cm}^{-2}$ for $6 \mathrm{MeV}$ electrons. Energetic proton treatment areas ranged from $0.8-3 \mathrm{~cm}^{2}$

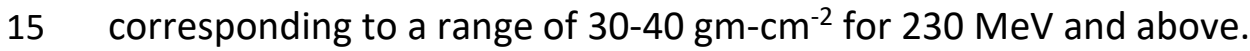

At least one critical review focused on non-differential tissue sparing results between

17 FLASH-RT and conventional radiotherapy (CONV-RT) experiments [ 6]. In a specific study, mice were irradiated with microbeam radiation therapy (MRT) using a synchrotron $95 \mathrm{keV}$ source [

19 25]. The MRT beam was made up of quasi-parallel micro-planar beams with a width of 25 to $20100 \mu \mathrm{m}$ that were typically spaced from 100 to $400 \mu \mathrm{m}$ (i.e., valleys). Dose rates in the beams 21 were between 276 to $319 \mathrm{~Gy}^{-\mathrm{s}^{-1}}$; scatter resulted in an order of magnitude lower dose rate 
1 (presumed to be $\approx 30 \mathrm{~Gy}^{-1} \mathrm{~s}^{-1}$ ) and total dose in the valleys. Toxicity post irradiation was

2 quantified by the $\mathrm{TD}_{50}$ metric based on $>15-20 \%$ weight loss, severe diarrhea, and moribund

3 behavior. What was striking about the conclusion was that the MRT FLASH valley total dose

4 (between 3.8-7.2 Gy at $\mathrm{TD}_{50}$ depending on irradiation site) was a better predictor of acute

5 toxicity, having roughly the same effects as total dose using conventional (0.05-0.06 Gy-s $\mathrm{s}^{-1}$ at 93

$6 \mathrm{keV}$ ) and synchrotron (37-41 Gy-s $\mathrm{s}^{-1}$ at $124 \mathrm{keV}$ ) delivery. Further, the total dose for TD50 at the

7 highest delivery rates increased as the treatment volume was reduced and were between 116-

8261 Gy greater. These results suggest that for FLASH-RT to be healthy tissue sparing, both the

9 periphery and exit edge of the radiation needs to be above the threshold required for the

10 effect; toxicity can be induced by low FLASH-RT dose rates. Further it also suggests that the

11 volume of low dose rate should be minimized.

To increase the treatment area, beam scanning has been proposed. But we were unable to clearly delineate between collimated and hard-edge beams so as to minimize the delivery

14 volume of below the FLASH-RT threshold. For a typical gaussian shaped beam resulting from a

15 non-zero emittance, the dose rate is significantly lower at the beam edges which may result in a reduced tissue sparing FLASH effect [ 6 25]. Thus, it is not clear if there are biological consequences of irradiating with FLASH contributions below $100 \%$ as the approach has only started to be explored; it is unknown how this approach will influence the overall effect [ 26]. seated tumors require the use of highly specialized and costly proton systems. Because of the 
1 more conformal to the tumor volume. But as of 2017 , only $1 \%$ of the world cancer patients are

2 treated with protons or heavy particles. And even though the modality was introduced in 1954

3 by Lawrence Berkeley National Laboratory, the primary limitation continues to be system cost $4 \quad$ (\$30-100M US) [ 27].

5

However, improvements in photon delivery have advanced. While intensity modulated spot scanning (IMPT-SS) using protons yields the most conformal external beam radiotherapy plans, photon therapy can be administered conformally if sufficient granularity is used. Previous studies using a pencil beam of photons with as few as three lines of sight yielded a $4 \%$ dose error over an idealized volume [ 28]. Helical tomotherapy (IMXT-HT) using fifty-one separate angles over $360^{\circ}$ with sixty-four binary controlled beamlets and delivered in a helix pattern was comparable to other forms of proton therapy such as distal gradient tracking (IMPT-DGT) [ 29]. Large treatment areas ( $\approx 350 \mathrm{~cm}^{2} @ 1 \mathrm{~m}$ as we will demonstrate here) and long range $\left(\approx 25 \mathrm{gm}-\mathrm{cm}^{-2}\right)$ can be achieved with megavolt $(\mathrm{MV})$ photons. Utilizing multi lines of sight for near conformal therapy, they can be an alternative to fill the void between shallow treatment with microwave linacs and deeper treatment with expensive proton therapy systems [6]. While many of the clinic scale FLASH-RT systems can be converted to MV photons, beam loading and fundamental beam stability limitations sets practical limits to below ampere level beams and low dose rates for single accelerator systems [ 30].

Clinic scale microwave accelerators rely on the longitudinal resonance of a sinusoidally varying electromagnetic field in parallel with the electron motion; electrons in resonance experience a net positive accelerating gradient (i.e., the energy gained by a charge particle per 
1 length of accelerator) [ 31]. To increase dose rates requires higher current. Higher currents,

2 however, affect the electromagnetic wave resonance with the electron longitudinal motion and

3 can result in a lower gradient [ 32 33]. In one example, an increase from 0.3-A peak current to

4 1.2-A peak current reduced the exit gradient from $12.7-\mathrm{MV}-\mathrm{m}^{-1}$ to $2.5-\mathrm{MV}-\mathrm{m}^{-1}$ resulting in lower

5 output energy [ 34]. Further, the beam break-up instability, which induces uncontrolled

6 transverse beam motion that causes the beam to be lost to the walls, scales as the square-root

7 of the beam current divided by the radius of the cavity [ 3536 ]. This effect can shorten the

8 beam pulse at higher currents.

An alternate acceleration technology, the linear induction accelerator (LIA), is based on a pulsed power approach and is mature [37]. It was developed in the 1960's to overcome the

11 beam current limitations in microwave linear accelerators. The systems are inherently FLASH,

12 high dose rate systems. When converted to bremsstrahlung, systems have demonstrated the 13 equivalent dose rates well in excess of the $100 \mathrm{~Gy}-\mathrm{s}^{-1}$ upper threshold.

The concept relies on magnetic induction (Fig. 3). A magnetic core surrounds an

15 evacuated accelerator tube where each core is enclosed within a conductive cavity. When a

16 pulse is applied to a winding around the core, a longitudinal electric field is generated. By

17 referencing one side of the pulsed source to the cavity interior, the electric field is net

18 accelerating as $\oint E \cdot d l=0$ everywhere except in line segment $B C$ (Fig. 3). This electric field is

19 maintained for the pulse duration so long as the magnetic core does not saturate (i.e., the point

20 at which leakage current around the core increases and the electric field collapses). This

21 saturation effect is based on the core material, the cross-sectional area, and the volt-second 
1 product of the applied pulse [38]. To return the core back to the original magnetic state after

2 the acceleration pulse, a small voltage opposite to the applied pulse is maintained across each

3 cavity.

The LIA is charge to mass ratio independent, only requiring that the pulsed sources be

5 synchronized, and the beam dynamics be properly managed. Experiments have demonstrated

6 high dose-rate ion beams ( $2 \mathrm{~A}$ of $\mathrm{He}^{+}, 2.4 \mathrm{~ns}$ pulse, and a $1 \mathrm{~mm}$ radius spot) using accelerator

7 cavities originally designed for electrons [ 3940 ]. Because the beam pipe radius can be

8 arbitrary, accelerating multiple beamlets through a single accelerator cavity enables

9 acceleration of multiple beams through a single accelerator [ 4142 ]. Such an approach greatly

10 simplifies a conformal FLASH-RT system. Since the beam pipe radius can be arbitrary,

11 suppression of beam instabilities is straightforward as the effect scales as the current divided by

12 the beam pipe radius squared [ 36].

To illustrate the extensive use of LIA technology, we list noteworthy systems with

energy >5-MeV in Table II [ 38424344454647484950515253 54]. These machines serve

15 as the basis for numerous other uses that include intense charged particle beam propagation,

16 free electron laser, dynamic FLASH radiography for weapons research, fusion experiments, and

17 pulsed radiation effects studies.

The LIA is a very simple and robust device and of relatively low cost. Because resonance

19 is not required to accelerate the charge particles, temperature fluctuations have a minor effect

20 on operation. While large and expensive accelerators are being proposed for investigating

21 FLASH-RT, developments in LIAs in recent years for other applications offer a wide range of 
compact and less expensive approaches that could be optimized for specific FLASH applications when they are established; some of these developments will be illustrated here [1]. Here we present an alternative accelerator technology for use in FLASH-RT.

\section{Results}

Photons generated by an LIA potentially provide broad area, deep penetrating, and high dose rate capability. To date, no MV broad beam photon sources have been characterized sufficiently to determine relevance to FLASH-RT. Here, we present experiments and measurements on the FLASH X-ray (FXR) accelerator used to accelerate electrons to $17 \mathrm{MeV}$ and also on the Experimental Test Accelerator-II (ETA-II) with a nominal output energy of 6.5 $\mathrm{MeV}$, but high repetition rate.

FXR is an active research facility mainly used for hydrodynamic experiments [55]. Conversion to bremsstrahlung is with a Ta target. The beam is approximately 70 ns FWHM long with a focal spot that is nominally $\approx 1.5 \mathrm{~mm}$ to ensure high resolution imaging. For MV photon FLASH-RT to be viable using any pulse format, the focus of the beam must be stable pulse to pulse. It is well known that even in ultra-high vacuum monolayer formation on the target is

rapid and scales in seconds as $\frac{3.2 \times 10^{-6}}{P}$, where $\mathrm{P}$ is the pressure in mbar. Once the beam impacts the surface, this monolayer, as well as gas impurities present even in highly purified metals, is released, and forms a plasma. Because the electron beam provides a strong negative potential, ions are extracted from the plasma boundary into the beam (Fig. $4 \mathrm{a}$ and $4 \mathrm{~b}$ ). The result is a dynamically varying focus on a prompt time scale. 
In Figure 4c, using a load lock transfer procedure, we performed analysis of the Ta

2 bremsstrahlung converter targets operated at $10^{-7}$ to $10^{-8} \mathrm{~T}$ in the accelerator. Prior to analysis,

3 an Au overcoating was used to confine and prevent contaminant introduction into the

4 measurements. With Rutherford backscattering (RBS) at $2 \mathrm{MeV} \mathrm{He}^{+}$, forward Rutherford

5 scattering (FRS), and secondary ion mass spectrometry (SIMS), we assayed the contamination

6 as $\mathrm{H}_{2} @ 1.5 \times 10^{15} \mathrm{~cm}^{-2}$ and $\mathrm{C} @ 3 \times 10^{15} \mathrm{~cm}^{-2}$ on the surface with 6 ppm $\mathrm{H}_{2}$ in the Ta matrix.

To determine the density of the contaminant ions created during the beam pulse, we

8 implemented high aspect ratio Faraday cups at various distances from the target (Fig. 4d). This

9 high aspect ratio was used to ensure measurement errors due to secondaries generated from

10 the ion impact were minimal. A negative bias ( $\approx-50 \mathrm{~V})$ stripped the low energy plasma electrons

11 from the measurement. For a Faraday cup stand-off distance of $25 \mathrm{~cm}$, we observed negative

12 scattered electrons during the beam pulse and fast ions approximately 90 ns after the beam

13 first impacts the target. It appeared that this fast ion pulse begins as the electron beam

14 terminates. On the slow time scale, we observe two components: one at $50 \mu$ s and another at

$1580 \mu \mathrm{s}$. Each of these components correspond to an apparent speed of approximately $280 \mathrm{~cm}$ -

$16 \mu \mathrm{s}^{-1}, 0.50 \mathrm{~cm}-\mu \mathrm{s}^{-1}$, and $0.31 \mathrm{~cm}-\mu \mathrm{s}^{-1}$, respectively which is in reasonable agreement with our

17 hydrodynamic models [56]. From these signatures and the Faraday cup distance, we estimate

18 the initial plasma density $>10^{17} \mathrm{~cm}^{-3}$ but falling off rapidly to approximately $<10^{12} \mathrm{~cm}^{-3}$ at about

19500 ns.

20

While the plasma is too slow to immediately impact the FLASH beam, the ions are not.

21 To determine the impact of the ions on the bremsstrahlung spot size, we used a multi-frame $x-$ 
1 ray pinhole camera (see Methods section). The gate times were evenly spaced within the

2 bremsstrahlung main FLASH pulse. What is clear from the first column of images (Fig. $4 \mathrm{e}$ ) is a

3 degradation of the focus in later frames. This effect manifests itself as a decreasing dose rate in

4 time (Fig. 4f-marked "unstable focus"). This effect is far too fast to correct electronically (i.e.,

5 readjusting the focusing magnetic field). However, by using the pinhole camera for beam

6 characterization and under focusing the beam (i.e., focused minimum beyond the target) we

7 were able to achieve a net uniform spot and constant dose rate (Fig $4 \mathrm{f}$ - marked "stable

8 focus"). Typical optimized spot size was approximately $1.5 \mathrm{~mm}$ FWHM.

With an optimized focus, we performed total dose measurements during the $70 \mathrm{~ns}$

pulse to determine the collimated flat field and the shot-to-shot repeatability. The geometry for

11 the measurement is shown in Figure 4g. This particular measurement consisted of the

12 bremsstrahlung converter target, a fast CVD diamond FLASH dose detector, an $8 \mathrm{~cm}$ thick low

13 energy filter, and either thermoluminescent (TLD) or film detector at 1-2 $m$ [ 57]. The CVD

14 diamond FLASH detector is range thin to the photons so as not to perturb the measurement.

15 Figure $4 \mathrm{~h}$ shows a flat field for $90-100 \%$ as approximately $21 \mathrm{~cm}$ diameter at $1 \mathrm{~m}$. This measurement corresponds to approximately a $350 \mathrm{~cm}^{2}$ area. We measured a $6^{\circ}$ half angle

17 through the collimator at $17 \mathrm{MeV}$ electron energy. The cone angle was a result of the

18 combination of the off normal electron trajectories and beam energy; the latter contribution

19 scales as $\frac{1}{\gamma}$ where $\gamma=1+\frac{E_{\text {beam }}}{m_{o} c^{2}},\left(E_{\text {beam }}-\right.$ incident beam energy, $m_{o} c^{2}-$ energy of an electron at 
To measure the pulse-to-pulse repeatability, we used the CVD diamond flash detector

2 immediately after the target. This detector provides a fast signal that is recorded. For

3 calibration we used an array of thermoluminescent dosimeters (TLDs). Bremsstrahlung was not

4 generated on all pulses. In Figure 4i, we measured the calibrated dose level and variation shot

5 to shot. In that measurement, we observe approximately $4.19 \mathrm{~Gy}$ total integrated dose in the

670 ns pulse with a variation of approximately $1 \sigma \approx 0.16$ corresponding to a $3.9 \%$ variation. This

7 value corresponds to an instantaneous dose rate of approximately $6 \times 10^{7} \mathrm{~Gy}-\mathrm{s}^{-1}$.

8 The experimental test accelerator (ETA-II) is a high repetition rate system reconfigurable

9 for accelerator development. It was designed to deliver highly stable electron beams with less than $1 \%$ energy variation, millimeter spot size, and submillimeter spot motion at 5,000 $\mathrm{Hz}$ (Fig.

$115 a$, upper). Initial use of the accelerator was in conjunction with a wiggler to generate

12 electromagnetic energy similar to ESRF and IMBL (Table I), but delivered $2 \mathrm{GW}$ at $140 \mathrm{GHz} \mathrm{mm}$ wave energy for fusion research studies [ 1617 58]. Because of the pulse width requirement that was based on an older design, the machine gradient was only $<0.5 \mathrm{MV}-\mathrm{m}^{-1}$. Here, we explore repetition rate operation of an LIA. The pulsed source for ETA-II

16 utilized thyratrons (Fig 5a, large cabinets) driving a Melville line (large vertical cylindrical

17 structure to the left) [59]. The overall schematic is shown in Figure 5b. A capacitor is charged and switched into the non-linear Melville transmission line. This pulse is sent through a step-up

19 transformer and series saturable inductors that successively compress the energy in time to 20 provide high peak power for each LIA core. At full voltage operation, the pulsed sources deliver 21 135-kV into a 2-ohm load at 5,000-Hz at better than $90 \%$ efficiency. Four pulsed sources were 
1 used to drive the accelerator; three drive sixty accelerator cavities and one drives the injector

2 to deliver nominally $\approx 3,000-\mathrm{A}$ electron beam at $6.5-\mathrm{MeV}$ in a 70 -ns pulse.

Stability of the system (pulse-to-pulse variation and output energy) is determined by the

4 state of the magnetic cores both in the accelerator and also in the pulsed sources. Excessive

5 internal reflected energy improperly returned the magnetics to a varying state (i.e., reset). We

6 observed the system to exhibit bipolar state behavior with large variations in timing. The upper

7 plot (Fig 5c) shows a multipulse burst from the pulsed source at $5,000 \mathrm{~Hz}$ where the $z$ axis is

8 pulse number. The timing variations in this data set were so large that five pulses of the burst

9 were outside the 2000 ns capture window. The data summary plot for timing (middle frame)

10 and pulse-to-pulse energy regulation (lower frame) are also shown in the figure. While the

11 timing variation was large, the pulse-to-pulse regulation was $1 \sigma<1 \%$. To achieve lower jitter, we

12 reduced reflected energy by better matching of the Melville line to the accelerator and also

13 used more aggressive damping in the core reset system. The final result is shown in Figure $5 \mathrm{~d}$.

14 Although a slight timing variation was seen for the first two pulses, the remaining pulses

15 showed a timing variation of $<5 \mathrm{~ns}$ while showing a pulse-to-pulse energy regulation of $\approx 0.5 \%$.

16 This result was confirmed with a magnetic energy analyzer at the end of the accelerator. If

17 converted to bremsstrahlung, the net dose rate variation would be $\pm 0.71 \%$.

We are presently designing and testing accelerator cavities with a goal to achieve higher

19 acceleration gradients. The experimental arrangement is shown in Figure 5e. These particular

20 cavities were initially insulated with SF6 pressurized gas which limited breakdown performance.

21 At this stage of testing, we were able to achieve $0.210 \mathrm{MV}$ across $0.165 \mathrm{~m}$ (Fig. $5 \mathrm{f}$ ) or $\approx 1.3 \mathrm{MV}$ - 
$1 \mathrm{~m}^{-1}$ for a pulse width of $40 \mathrm{~ns}$ FWHM. This gradient is approximately 2-3 times the gradient of

2 ETA-II and with oil insulation, we expect to achieve another doubling of that gradient.

To replace the existing pulsed source, we are testing high repetition rate, single crystal,

4 semi-insulating SiC photoswitches driven by pulsed laser diodes (Fig. 5g-5h) [ 60]. We have also

5 tested and utilized a configuration that charges capacitors in parallel and selectively discharges

6 them in series to allow output voltage variability, and hence variable control of the electron

7 final energy over a wide range [61]. Figure $5 \mathrm{~g}$ shows a device under test in a low inductance

8 geometry. In this particular geometry, the SiC (upper left inset) was integrated into a polyimide

9 epoxy structure. This particular structure has been tested to approximately $30 \mathrm{kV}$ under oil.

10 Contacts were evaporated gold. The diode laser and driver are shown in the larger photo; the

11 surface mount laser diode is shown in the upper right inset. Scale is $1 \mathrm{~mm}$ spacings. This

12 particular diode was rated for $70 \mathrm{~W}$ pulsed output in the IR spectrum with a $0.1 \%$ duty cycle.

13 Figure $5 \mathrm{~h}$ shows the output at $1 \mathrm{MHz}$ pulse repetition frequency. Risetime was approximately

$1412 \mathrm{~ns}$ and was limited by the diode driver circuit.

15

16 Discussion

The MRT results using a synchrotron at $95 \mathrm{keV}$ suggests that both the periphery and exit dose rate need to be above the healthy tissue sparing threshold to minimize toxicity [ 25]. Based on this conclusion, we developed an approach for a FLASH-RT system using an LIA (Fig. 6)

20 by first calculating the dose rate distribution for two cases. The first case was a single source at $21100 \mathrm{~Gy}^{-1} \mathrm{~s}^{-1}$ at $1 \mathrm{~m}$ (Fig. 6a). The second case was four separate sources placed symmetrically 
1 around the volume, each at $25 \mathrm{~Gy}-\mathrm{s}^{-1}$ at $1 \mathrm{~m}$ (Fig. $6 \mathrm{~b}$ ) or $100 \mathrm{~Gy}-\mathrm{s}^{-1}$ total. Each case relied on

2 percent depth dose (PDD) experimental curves [ 62 63]. For simplicity, we used an idealized

3 cylindrical volume with the mean value of the human abdominal circumference of $\approx 1 \mathrm{~m}$ or

4 radius of $\approx 16 \mathrm{~cm}$ [ 64]. Source surface distance (SSD) was $1 \mathrm{~m}$ for all sources. Electron energy

5 was $16 \mathrm{MeV}$. Conversion to bremsstrahlung was based on a Ta target.

In Figure 6a, while a heathy tissue sparing dose rate $>40 \mathrm{~Gy}^{-1} \mathrm{~s}^{-1}$ is delivered nearest the

7 source, about $25 \%$ of the volume is below that dose rate. In Figure $6 b$, a symmetric

8 configuration of four sources achieved $50 \%$ beyond the required healthy tissue sparing dose

9 rate, or about $60 \mathrm{~Gy}-\mathrm{s}^{-1}$ throughout the majority of the volume. The minimum dose rate in that volume decreases slightly to about $56 \mathrm{~Gy}-\mathrm{s}^{-1}$ in the center of the volume. While dose build up

11 was considered using the deposition curves, dose rate at the volume edge increased rapidly to

$1240 \mathrm{~Gy}-\mathrm{s}^{-1}$ in $1-2 \mathrm{~cm}$ because of the added contribution from the other sources. This result

13 suggests that for MV bremsstrahlung FLASH-RT, multibeam delivery is necessary to remain

14 above the healthy tissue sparing threshold. Thus, we baseline our approach using four sources,

15 but to minimize the possibility of loss of a source, resulting in below the healthy tissue sparing

16 dose rate, we rely on a single accelerator generating all of the separate beamlets.

We have demonstrated conversion of the electron beam to bremsstrahlung using Ta on both FXR and ETA-II and presented measurements of the physical processes of the beam-target

19 interaction to produce a predictable through collimator dose. The measurement showed a

20 uniform field of $\approx 350 \mathrm{~cm}^{2}$ at $1 \mathrm{~m}$ with a dose $\approx 4.2$ Gy per pulse integrated over $70 \mathrm{~ns}$.

21 Instantaneous dose rate was $\approx 6 \times 10^{7} \mathrm{~Gy}-\mathrm{s}^{-1}$. The pulse-to-pulse variation was $1 \sigma \approx 0.16$ or a 
$13.9 \%$. This result is in contrast with the largest FLASH-RT field to date of a $55 \mathrm{~cm}^{2}$ field using

2 electrons [9].

On ETA-II, we demonstrated stable operation at $5 \mathrm{kHz}$ both in timing $(<5 \mathrm{~ns})$ and energy

4 variation delivered by the pulsed source $(<0.5 \%)$.

$5 \quad$ Using photonic switches, we demonstrated $1 \mathrm{MHz}$ repetition rates. Using the

6 controllability of the device, the pulsed sources can be simplified to provide electron energy

7 variability.

Here we use a $1.5 \mathrm{~mm}$ spot diameter and four separate beamlets to approximate

9 conformal therapy; added beamlets reduce the bremsstrahlung converter requirement for a

10 given dose rate. For scaling, we use the well-known relationship of electrons to bremsstrahlung

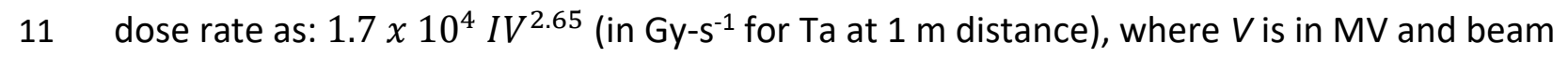

12 current $I$, is in $\mathrm{kA}$.

The pulsed beams delivered for our ETA-II measurement had an instantaneous power

14 density on the Ta target $\approx 10^{12}-10^{13} \mathrm{~W}-\mathrm{cm}^{-3}$. At these power densities, the target undergoes

15 rapid hydrodynamic expansion on the microsecond time scale and is therefore single use.

16 FLASH-RT requires a minimum average dose-rate of only 40 to $100 \mathrm{~Gy}-\mathrm{s}^{-1}$ while maintaining the

17 instantaneous dose rate $10^{1}-10^{2}$ times lower or $\approx 10^{6} \mathrm{~Gy}-\mathrm{s}^{-1}[6]$. These lower rates allow using

18 electron beam repetition rate as a free parameter for the target approach.

Short duty cycle ( $\approx 30$ s) DC x-ray tubes using thermal inertia have achieved almost 200

$20 \mathrm{~kW}-\mathrm{cm}^{-2}[65] .25 \mathrm{~Gy}-\mathrm{s}^{-1}$ total requires a $6.25 \mathrm{~A}$ beam at a $10 \mathrm{kHz}$ rate with $15 \mathrm{~ns}$ pulses on each 
1 of the converter targets (Methods section). For a $1.5 \mathrm{~mm}$ spot size, the instantaneous power

2 flux is $850 \mathrm{~kW}-\mathrm{cm}^{-2}$ which is still clearly outside the range of present state-of the-art.

Two target approaches are still possible: Heat generated from a $1.5 \mathrm{~mm}$ electron spot

4 size at $16 \mathrm{MeV}$ and $6.25 \mathrm{~A}$ can be dissipated by rotating the target at an equivalent linear speed

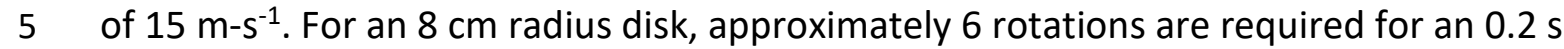

6 treatment cycle of $20 \mathrm{~Gy}$. Net local temperature rise is $725^{\circ} \mathrm{C}$ and well within the Ta melting

7 temperature of $3017^{\circ} \mathrm{C}$. For simplification, as a second approach, we modeled a liquid cooled

8 multilayer target where each layer is designed to absorb $\approx 4 \%$ of the electron beam energy

9 (total of 25 layers) [ 66]. In this model, each layer is allowed to convect heat away into a moving

10 fluid (Fig 6c-6d). For the fluid, we assumed a convective heat transfer coefficient of $100 \mathrm{~W}-\mathrm{m}^{-2}$ -

$11{ }^{\circ} \mathrm{K}^{-1}$, a flow rate of $4.2 \mathrm{~cm}-\mathrm{s}^{-1}$ and allowed a $50^{\circ} \mathrm{C}$ temperature rise. Peak equilibrium

12 temperature is approximately $110^{\circ} \mathrm{C}$.

The high gradient LIA cavity concept is shown in Figure 6e, where the gradient is given

14 by: $\alpha \partial B \frac{R_{o}-R_{i}}{\tau}$, where $\alpha$ is the packing efficiency, $\partial B$ is the flux swing of the cores, $R_{o}$ and $R_{i}$ are

15 the magnetic core outer and inner diameters, respectively, and $\tau$ is pulse width [ 67]. To provide

16 the insulator interface between the magnetic core and vacuum region for the electron beam,

17 we use multilayer insulators. These structures are made up of periodic layers of conductive and

18 insulating material laminated into a monolithic structure. The structure provides an increase in

19 breakdown electric field of up to $4 x$, is insensitive to polarity effects, photon and charge particle

20 flux, and suppresses beam breakup instability resonances [ 686970 71]. 
To allow enough room for multiple beams while keeping the cavity small to avoid

2

3

4

5

6

7

8

9

10

11

12

13

14

unwanted beam breakup modes, we select a ferrite inner radius of $R_{i}=0.1-\mathrm{m}$. We also take, $\partial \mathrm{B}$ $\approx 0.6 \mathrm{~T}$ ( NiZn ferrite), and $\alpha=60 \%$ because of the insulator configuration [ 38]. The surface for the optimization trading $\tau$ and $R_{i}$ to achieve a given gradient is shown in Figure $6 \mathrm{f}$. We show a design point of $5 \mathrm{MV} / \mathrm{m}$ at a $15 \mathrm{~ns}$ pulse width for $R_{0} \approx 0.3 \mathrm{~m}$.

(1)

A single LIA is used to accelerate separate beamlets in an approximately $14 \mathrm{~cm}$ diameter beam pipe. While four beams are shown, eight can be easily implemented. Beam transport is managed through the accelerator with solenoid coils and integrated steering similar to FXR [

55]. The added steering capability enables generating of oblique rays to allow a closer approximation of multibeam conformal therapy. At $16 \mathrm{MeV}$, the system would be approximately $3.2 \mathrm{~m}$ long (Fig. $6 \mathrm{~g}$ ) delivering an average dose rate of $60 \mathrm{~Gy}-\mathrm{s}^{-1}$ through an idealized $16 \mathrm{~cm}$ radius volume.

\section{Methods}

We developed Figure 2 and Table I by performing an exhaustive search of FLASH-RT systems in the open literature leveraging the work of Esplen, Wilson, and Darafsheh [ 67 22]. In an attempt to standardize our methodology, we used spot size, range at energy, and average beam current to determine dose rates. For electron range, we used stopping power data from M.O. El-Ghosssain over four tissue types [ 72]. For bremsstrahlung photons, we used the PDD data by Hill for low energy and those by Narayanasamy and Feye for MV energy [ 6263 73]. The intense photon sources at ESRF and IMBL use wigglers. The spectra provided were 
1 bremsstrahlung-like to first order and sufficient for this parameter survey; no added corrections

2 were made. Turner provided the correction between a water phantom and tissue; again, no

3 changes were necessary for our estimates [ 74].

$4 \quad$ For our dose-rate calculations, we used one range depth (i.e., $1 / I_{0} \approx \mathrm{e}^{-1}$ ) for electrons and

5 photons. For protons, where the data was provided, we used the $10 \%$ point of the distal edge

6 enclosing the Bragg peak at energy using the dose depth curves from Kang for the energy 28-

$7227 \mathrm{MeV}$ [ 75]. As those data were taken with water, we scaled to range data for tissue by Usta

8 averaging over eight tissue types [ 76].

The $\mathrm{x}$-ray pinhole camera for FXR was designed and built for measuring the $\mathrm{x}$-ray spot size as a function of time. It consisted of a "pinhole" composed of a series of tungsten cylinders stacked in a $15 \mathrm{~cm}$ long stainless-steel holder. Each cylinder had a hole formed by EDM, ranging in diameter from 200 to $760 \mu \mathrm{m}$. The cylinders were stacked to approximate a double-tapered cone, with a section of $200 \mu \mathrm{m}$ pinholes by $4 \mathrm{~cm}$ long in the center. Behind the single pinhole, the camera had four gated channels that record the x-ray images to CCD cameras. Each of the channels had a scintillator array to convert the x-rays to visible light, a mirror and relay lens to image the scintillator onto the input of a microchannel image intensifier, and a CCD camera fiberoptically coupled to the output of the intensifier. The unit was shielded from external radiation using W powder packed between aluminum plates. Each camera had a frame buffer that stores the image for readout after each shot. The cameras had standard analog video output, but it was transmitted to the FXR control room via a 4-channel fiber-optic link. Arming of the camera frame buffers was also done through this fiber optic link. The video was digitized by a Scion frame- 
1 grabber and computer. NIH Image J was used for local analysis of the images. Calibration was

2 done with geometric considerations and cross correlating the results with other spot size

3 measuring techniques such a observing the blur over an opaque edge.

$4 \quad$ Simplified dose rate distributions were developed using experimental PDD curves at the

5 proper energy. This approach takes the dose build up zone into account as well as the

6 bremsstrahlung spectrum. The calculations were done in 2D using standard ray tracing

7 techniques to each $\approx \mathrm{cm}$ sized voxel. The array was then processed to provide the dose map. In

8 addition, we used numerical approximations to crosscheck our results. Namely we use: $I_{T}=$

$9 \quad \sum_{i=1}^{N} I_{i}$, where $I_{T}$ is the total dose rate and $I_{i}$ is each source rate $i$. In the dose fall off region, we

10 estimate the dose rate as a function of depth using an exponential function; the PDD curves

11 correlated well to this function, with $\chi^{2}=0.9997$.

13 or preferably $>100 \mathrm{~Gy}-\mathrm{s}^{-1}$. While it is not completely clear what the instantaneous dose rate

14 should be, some suggest $\approx 10^{6} \mathrm{~Gy}-\mathrm{s}^{-1}[6]$. Our goal is high gradient requiring that the pulse width

15 of the LIA be kept as short as possible but is limited by magnetic core response. Typical

16 response is as fast as 6-8 ns [ 77]. This result allows a practical minimum pulse width of

17 approximately $15 \mathrm{~ns}$. As stated earlier, our calculation is based on electrons to bremsstrahlung

18 instantaneous dose rate scaling as: $1.7 \times 10^{4} I V^{2.65}$, where $V$ is in $\mathrm{MV}$ and beam current $I$, is in

$19 \mathrm{KA}$ and is a relatively good predictor for dose rate in $\mathrm{Gy}-\mathrm{s}^{-1}$ for Ta at $1 \mathrm{~m}$ distance. Instantaneous

20 dose rate is thus defined by the current and electron energy and average dose rate is

21 determined by the pulse repetition rate and pulse width. 
References

1. Feder, T., High radiation dose rates may improve cancer therapy. Physics today 73 (12), 24-26 (2020).

2. Vozenin, M.-C. et al., The Advantage of FLASH Radiotherapy Confirmed in Mini-pig and Cat-cancer Patients. Clin Cancer Res 25 (1), 35-42 (2019).

3. Schuler, E. et al., Experimental Platform for Ultra-high Dose Rate FLASH Irradiation of Small Animals Using a Clinical Linear Accelerator. Int J of Rad Oncology Biol Phys 97 (1), 195-203 (2017).

4. Montay-Gruel, P. et al., Irradiation in a flash: Unique sparing of memory in mice after whole brain irradiation with dose rates above $100 \mathrm{~Gy} / \mathrm{s}$. Radiotherapy and Oncology 124 (3), 365-369 (2017).

5. Zlobinskaya, O. et al., The Effects of Ultra-High Dose Rate Proton Irradiation on Growth Delay in the Treatment of Human Tumor Xenografts in Nude Mice. Radiat. Res. 181 (2), 177-183 (2014).

6. Wilson, J. D., Hammond, E. M., Higgins, G. S. \& Petersson, K., Ultra-High Dose Rate (FLASH) Radiotherapy: Silver Bullet or Fool's Gold? Front. Oncology 9, 1563 (2020).

7. Esplen, N., Mendonca, M. S. \& Bazalova-Carter, M., Physics and biology of ultrahigh dose-rate (FLASH) radiotherapy: a topical review. Phys. Med. Biol. 65 (23), 1-37 (2020).

8. Bourhis, J. et al., Treatment of a first patient with FLASH-radiotherapy. Radiotherapy and Oncology 139, 18-22 (2019).

9. Jaccard, et al., High dose-per-pulse electron beam dosimetry: Commissioning of the Oriatron eRT6 prototype linear accelerator for preclinical use. Med. phys. 45 (2), 863-874 (2018).

10. Mole, R. H., The LD50 for uniform low LET irradiation of man. British J. Radiology 57 (677), 355-369 (1984).

11. Berry, R. J., Hall, E. J., Forster, D. W., Storr, T. H. \& Goodman, M. J., Survival of mammalian cells exposed to X rays at ultra-high dose-rates. British J. Radiology 42 (494), 102-107 (1969).

12. Maxim, P. G., Keall, P. \& Cai, J., Point/Counterpoint, FLASH radiotherapy: Newsflash or flash in the pan? Med. Phys. 46 (10), 4287-4290 (2019).

13. Favaudon, V. et al., Ultrahigh dose-rate FLASH irradiation increases the differential response between normal and tumor tissue in mice. Sci. Transl. Med. 6 (245), 245ra93 (2014).

14. Karsch, L. et al., Dose rate dependence for different dosimeters and detectors: TLD, OSL, EBT films, and diamond detectors. Med. Phys. 39 (5), 2447-2455 (2012).

15. Lempart, M. et al., Modifying a clinical linear accelerator for delivery of ultra-high dose rate irradiation. Radiotherapy Oncology 139, 40-45 (2019). 
16. Crosbie, J. C. et al., Energy spectra considerations for synchrotron radiotherapy trials on the ID17 bio-medical beamline at the European Synchrotron Radiation Facility. J. Synchrotron Rad. 22, 10351041 (2015).

17. Archer, J. et al., High spatial resolution scintillator dosimetry of synchrotron microbeams. Sci. Rep. 9, 6873 (2019).

18. Bazalova-Carter, M. \& Esplen, N., On the capabilities of conventional x-ray tubes to deliver ultrahigh (FLASH). Med. Phys. 46 (12), 5690-5695 (2019).

19. Van de Walle, J. et al., The SCC@: from source to extraction, presented at Proceedings of Cyclotrons 2016, Zurich, Switzerland, 2016 (unpublished).

20. Henrotin, S. et al., Commissioning and testing of the first IBA S2C2, presented at Proceedings of Cyclotrons 2016, Zurich, Switzerland, 2016 (unpublished).

21. Zwart, T. et al., Developing a modern, high-quality proton therapy medical device with a compact superconducting synchrocyclotron, presented at Centro de Investigaciones Energeticas, Medioambientales y Tecnologicas (CIEMT) 2016, Madrid, Spain, 2016 (unpublished).

22. Darafsheh, A. et al., Feasibility of proton FLASH irradiation using a synchrocyclotron for preclinical studies. Med. Phy. Lett. 47 (9), 4348-4355 (2020).

23. Girdhani, S. et al., FLASH: A novel paradigm changing tumor irradiation platform that enhances therapeutic ratio by reducing normal tissue toxicity and activating immune pathways, presented at American Association for Cancer Research Annual Meeting 2019, Atlanta, GA USA, 2019 (unpublished).

24. Dollinger, G. et al., Nanosecond pulsed proton microbeam. Nucl. Instr. Meth. Phys. Res. B 267, 2008-2012 (2009).

25. Smyth, L. M. L. et al., Comparative toxicity of synchrotron and conventional radiation therapy based on total and partial body irradiation in a murine model. Sci. Rep. 8, 12044 (2018).

26. van Marlen, P. et al., Bringing FLASH to the clinic: Treatment planning considerations for ultrahigh dose-rate proton beams. Int. J. Radiation Oncol. Biol. Phys. 106 (3), 621-629 (2020).

27. Mohan, R. \& Grosshans, D., Proton therapy - Present and future. Adv. Drug Del. Rev. 109, 26-44 (2017).

28. Holmes, T. \& Mackie, T. R., A filtered backprojection dose calculation method for inverse treatment planning. Med. Phys. 21 (2), 303-313 (1994).

29. Flynn, R. T., Barbee, D. L., Mackie, T. R. \& Jeraj, R., Comparison of intensity modulated x-ray therapy and intensity modulated proton therapy for selective subvolume boosting: a phantom study. Phys. Med. Biol. 52, 6073-6090 (2007). 
30. Maxim, P. G., Tantawi, S. G. \& Loo, B. W., PHASER: A platform for clinical translation of FLASH cancer radiotherapy. Radiotherapy and Oncology 139, 28-33 (2019).

31. Ginzton, E. L., Hansen, W. W. \& Kennedy, W. R., A linear electron accelerator. Rev. Sc. Instr. 19, 89108 (1948).

32. Neal, R. B., Design of linear electron accelerators with beam loading. J. Appl. Phys. 26 (7), 10191024 (1958).

33. Khizhnyak, N. A., Tolok, V. T., Chechkin, V. V. \& Nazarov, N. I., The acceleration of large current pulses in electron linear accelerators. Plasma Physics (J. Nucl. Ener. C) 4, 129-134 (1962).

34. Uetomi, I., Yamazaki, M., Kobayashi, H. \& Sato, I., Extended Theory of Beam Loading in Electron Linac. Jpn. J. Appl. Phys. 32 (6A), 2858-2864 (1993).

35. Panofsky, W. K. H. \& Bander, M., Asymptotic theory of beam break-up in linear accelerators. Re. Sci. Instr. 39 (2), 206-212 (1968).

36. Humphries, S., Charged Particle Beams (John Wiley and Sons, Hoboken, NJ, 1990).

37. Christofilos, N. C. et al., High current linear induction accelerator for electrons. Rev. Sci. Instr. 35 (7), 886-890 (1964).

38. Takayama, K. \& Briggs, R. J., Induction Accelerators (Springer, New York, 2011).

39. Seidl, et al., Irradiation of materials with short, intense ion pulses at NDCX-II. Laser and Part. Beams 35 (2), 373-378 (2017).

40. Waldron, W. L. et al., The NDCX-II engineering design. Nucl. Instr. Meth. Phys. Res. A 733, 226-232 (2014).

41. Barnard, J. J. et al., Induction accelerator architectures for heavy-ion fusion. Nucl. Instr. Meth. in Phys. Res. A 415 (1-2), 218-228 (1998).

42. Smith, J. R., Bailey, V. L., Lackner, H. \& Putnam, S. D., Performance of the spiral line induction accelerator, presented at Proceedings of the 1997 Particle Accelerator Conference, Vancouver, BC Canada, 1997 (unpublished).

43. Beal, J. W., Christofilos, N. C. \& Hester, R. E., The Astron Linear Accelerator. IEEE Trans. Nucl. Sci. 16 (3), 294-298 (1969).

44. Allen, S. L. et al., Generation of high power $140 \mathrm{GHz}$ microwaves with an FEL for the MTX experiment, presented at Proceedings of International Conference on Particle Accelerators, Washington, DC USA, 1993 (unpublished). 
45. Yatsui, K. et al., Pulse-power technology and its applications at LBT, Nagaoka, presented at 11th International Conference on High-Power Particle Beams, Prague, Czech Republic, 1996 (unpublished).

46. Anthouard, P. et al., Airix at CESTA, presented at 11th International Conference on High-Power Particle Beams, Prague, Czech Republic, 1996 (unpublished).

47. Fateev, A. A. et al., Status of the first stage of linear induction accelerator SILUND-21, presented at Proceedings Particle Accelerator Conference, Dallas, TX USA, 1995 (unpublished).

48. Deng, J. et al., Upgrading of Linear Induction Accelerator X-Ray Facility (LIAXF), presented at 19th International Linear Accelerator Conference, Chicago, IL USA, 1998 (unpublished).

49. Kulke, B. \& Kihara, R., Recent Performance Improvements on FXR. IEEE Trans. Nucl. Sci. 30 (4), 3030-3032 (1983).

50. Burns, M. J. et al., Status of the DARHT phase 2 long-pulse accelerator, presented at 2001 Particle Accelerator Conference, Chicago, IL USA, 2001 (unpublished).

51. Burns, M. J. et al., DAHRT accelerators update and plans for initial operation, presented at Particle Accelerator Conference, New York, NY USA, 1999 (unpublished).

52. Merle, E. et al., Installation of the AIRIX Induction Accelerator, presented at 19th International Linear Accelerator Conference, Chicago, IL USA, 1998 (unpublished).

53. Deng, J. et al., Design of the DRAGON-I Linear Induction Accelerator, presented at 21st International Linear Accelerator Conference, Gyeongju, Korea, 2002 (unpublished).

54. Reginato, L., The Advanced Test Accelerator (ATA), a 50-MeV 10-kA Induction Linac. IEEE Trans. Nucl. Sci. 30, 2970-2974 (1983).

55. Multhauf, L. G., Back, N. L., Simmons, L. F., Zentler, J.-M. \& Scarpetti, R. D., Invited: The LLNL flash xray induction linear accelerator (FXR), presented at Proc. SPIE 4948, 25th International Congress on High-Speed Photography and Photonics, Beaune, France, 2003 (unpublished).

56. Darwin, D.-M. H., 1999.

57. Negre, J. P. \& Rubbelynck, C., Application of fast CVD diamond photoconductor detectors to MeV Xray metrology for the AIRIX fash radiographic facility. Nucl. Instr. Meth. Phys. Res. A 451, 638-650 (2000).

58. Thumm, M., State-of-the-Art of High-Power Gyro-Devices and Free Electron Masers. J. Infrared Milli Terahz Waves 41, 1-140 (2020). 
59. Sampayan, S. et al., Performance characteristics of an induction linac magnetic pulse compression modulator at multi-kilohertz pulse repetition frequencies, presented at IEEE Particle Accelerator Conference, San Francisco, CA USA, 1991 (unpublished).

60. Sampayan, S. E. et al., Characterization of carrier behavior in photonically excited $6 \mathrm{H}$ silicon carbide exhibiting fast, high voltage, bulk transconductance properties. Sci. Rep. 11, 6859 (2021).

61. Sampayan, S. E., US Patent No. 10,270,368 (April 2019).

62. Narayanasamy, G. et al., Commissioning an Elekta Versa HD linear accelerator. J. Appl. Clinical Med. Phys. 17 (1), 179-191 (2016).

63. Feye, A. T., Percentage depth dose and beam profile measurements for electron and photon beam in reference field size for different energies. Intl. J. Sci. Engr. Res. 9 (2), 1460-1464 (2018).

64. Fryar, C. D., Kruszon-Moran, D., Gu, Q. \& Ogden, C. L., 2018.

65. Schulz, J. W., Innovation in X-Ray technology. Revista Matéria 16 (4), 867-876 (2011).

66. Dalakos, G. T., Frontera, M. A. \& Robinson, V. S., United States Patent No. 9,715,989 B2 (July 2017).

67. Humphries, S., Principals of Charged Particle Acceleration (John Wiley and Sons, Hoboken, NJ, 1999).

68. Sampayan, S. E., Vitello, P. A., Krogh, M. L. \& Elizondo, J. M., Multilayer high gradient insulator technology. IEEE Trans. Dielect. Elect. Insul. 7 (3), 334-339 (2000).

69. Sampayan, S. E., Caporaso, G. J., Houck, T. L. \& Watson, J. A., Multilayer high gradient insulator testing in the vicinity of charged particle beams. (to be published).

70. Harris, J. R., Kendig, M., Poole, B., Sanders, D. M. \& Caporaso, G. J., Electrical strength of multilayer insulators. Appl. Phys. Lett 93, 241502 (2008).

71. Shang, C. C. et al., BBU design of linear induction accelerator cells for radiography application, presented at 1997 Particle Accelerator Conference, Vancouver, BC Canada, 1997 (unpublished).

72. El-Ghossain, M. O., Calculations of stopping power, and range of ions radiation (alpha particles) interaction with different materials and human body parts. Int. J. of Phys. 5 (3), 92-98 (2017).

73. Hill, R. et al., Advances in kilovoltage x-ray beam dosimetry. Phys. Med. Biol. 59 (6), 183-231 (2014).

74. Turner, J. E., Atoms, Radiation, and Radiation Protection (Wiley, Inc., Hoboken, NJ, USA, 2008).

75. Kang, M., Cessac, R. \& Pang, D., Commissioning and beam characterization of the first gantrymounted accelerator pencil beam scanning proton system. Med. Phys. 47, 3496-3510 (2020). 
76. Usta, M. \& Tufan, M. Ç., Stopping power and range calculations in human tissues by using the Hartree-Fock-Roothaan wave functions. Rad. Phys. Chem. 140, 43-50 (2017).

77. Corcoran, P. et al., Experimental tests of the power supply and prototype cell for the 1.5 MeV SLIA acceleration unit, presented at 1991 IEEE Particle Accelerator Conference, San Francisco, CA USA, 1991 (unpublished). 

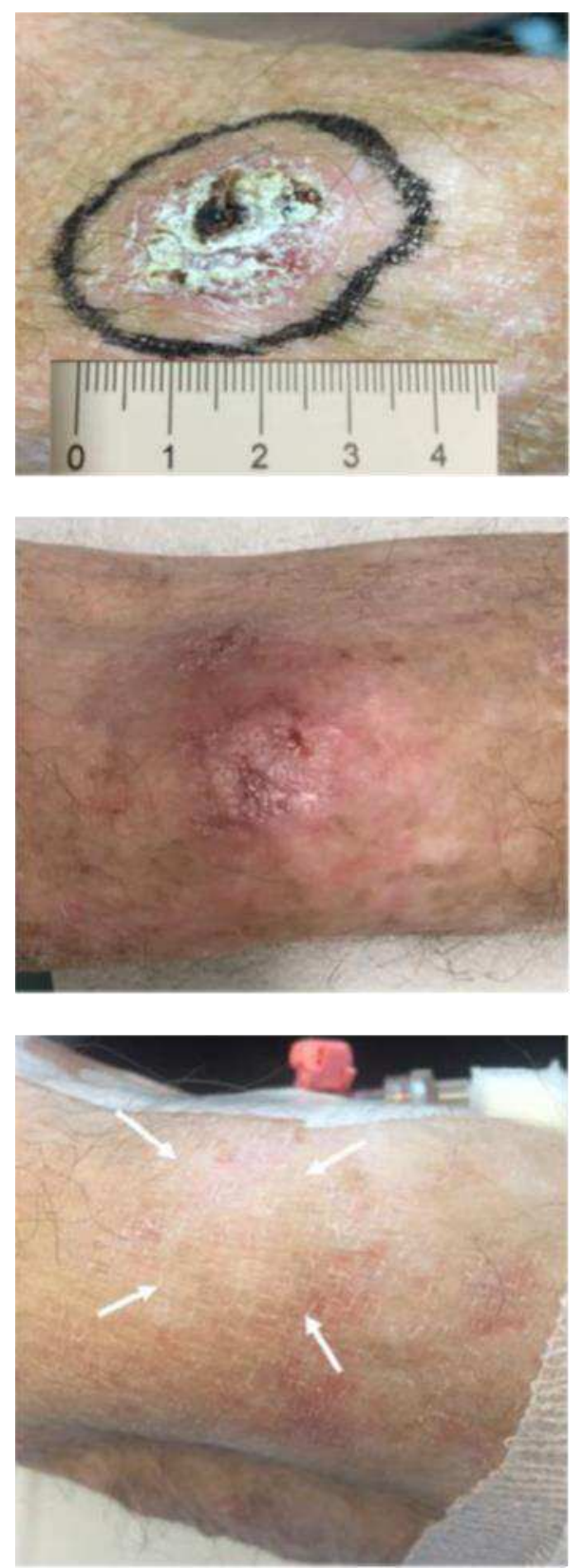

2 Figure 1 - Effects of $167 \mathrm{GY} / \mathrm{s}$ (15-Gy in 90-ms) electron beam treatment of a 3.5-cm skin tumor 3 in the first FLASH-RT of a human subject. Top: Day 0, middle: Day 21, bottom: Day 150 [ 8 ] 4 (Reprinted with permission, License No. 5054930939964). 


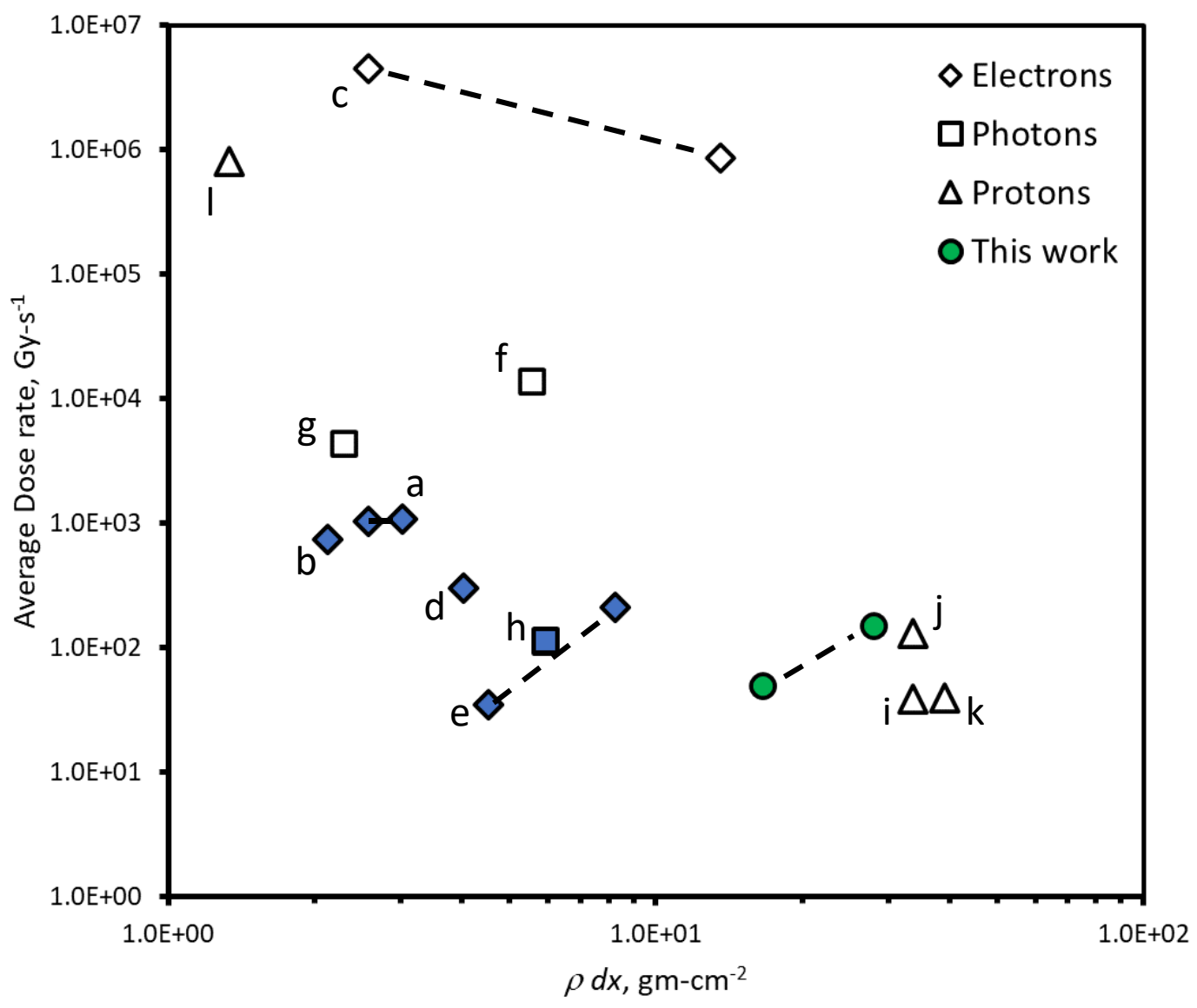

1

2 Figure 2 - A survey of FLASH-RT average dose rate as a function of range calculated from details 3 obtained from the literature. See Table I for specific details. Solid blue markers designate clinic 4 scale systems that can be placed in approximately a $100 \mathrm{~m}^{3}$ radiation vault. Dotted line signifies 5 the approximate range of a particular single system. 


$$
U=q \oint \boldsymbol{E} \cdot d \boldsymbol{l}
$$

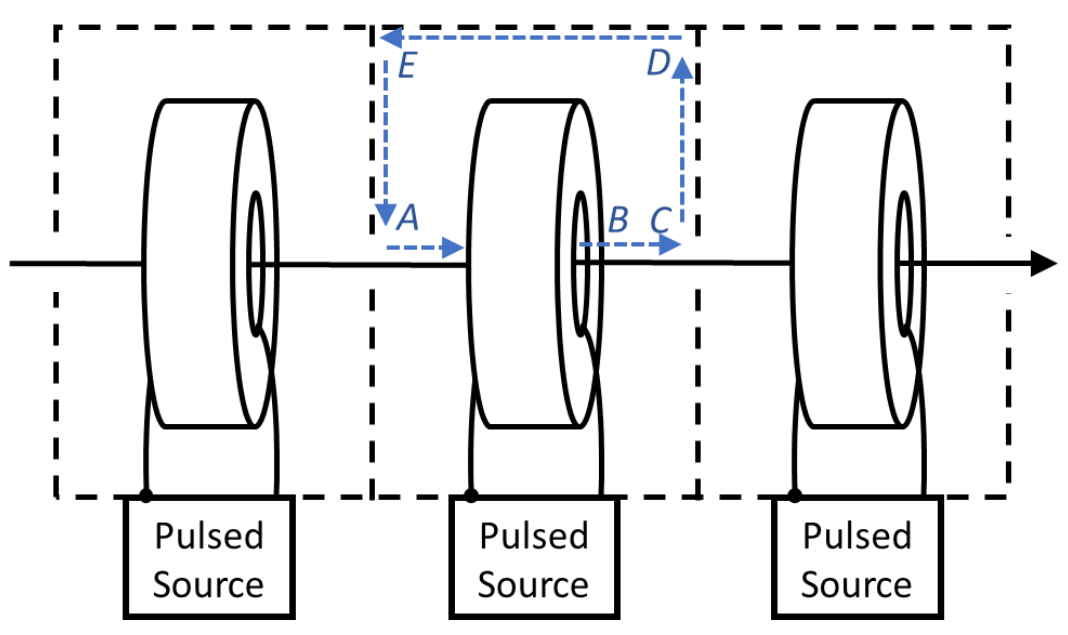

3 Figure 3 - Acceleration of charged particles (on axis arrow) with a linear induction accelerator

4 (LIA). Here $U$ is the energy gain, $q$ is the particle charge, and $\boldsymbol{E}$ is the electric field. Magnetic 5 cores are depicted by the toroids and the dotted lines indicate conductive surfaces. One side of 6 the pulsed source is referenced to the accelerator cavity interior (represented by the dot). The 7 electric field outside the structure is everywhere essentially zero within the diffusion time 8 scales of the conductive walls. Thus, the line integral is zero from segments $C$ to $A$ as the 9 electric field is shorted by the conducting wall. The contribution along $A B$ is also zero as the 10 pulsed source output is referenced to the cavity wall. The only contribution is along line segment $\mathrm{BC}$, where charge particles gain energy during the pulse. $N$ cavities are arranged in series to provide a total acceleration of $N V_{\text {pulsed source. }}$ 
1

a

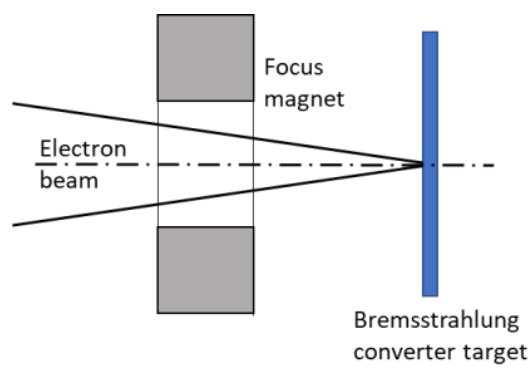

2

C

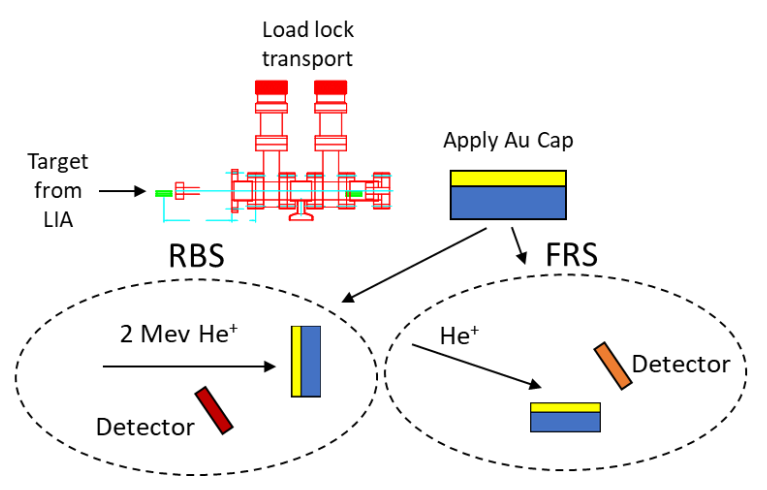

e

3

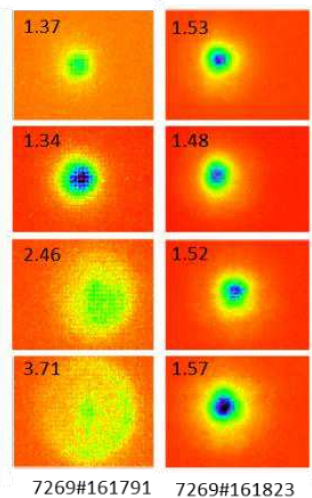

b

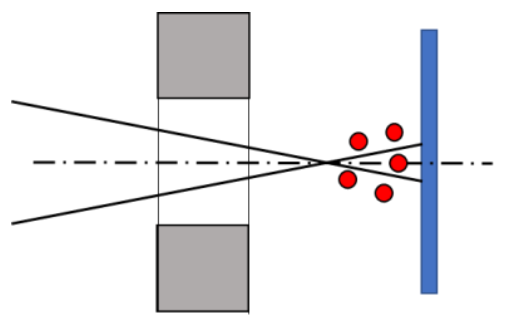

d
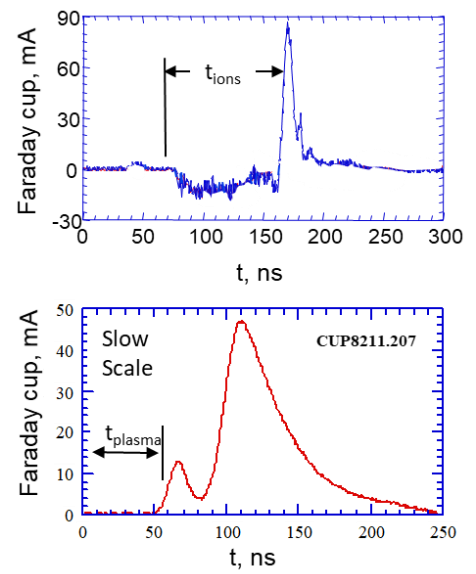

f

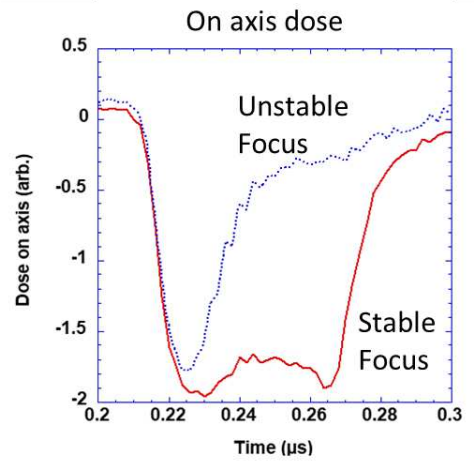

4

\section{g}

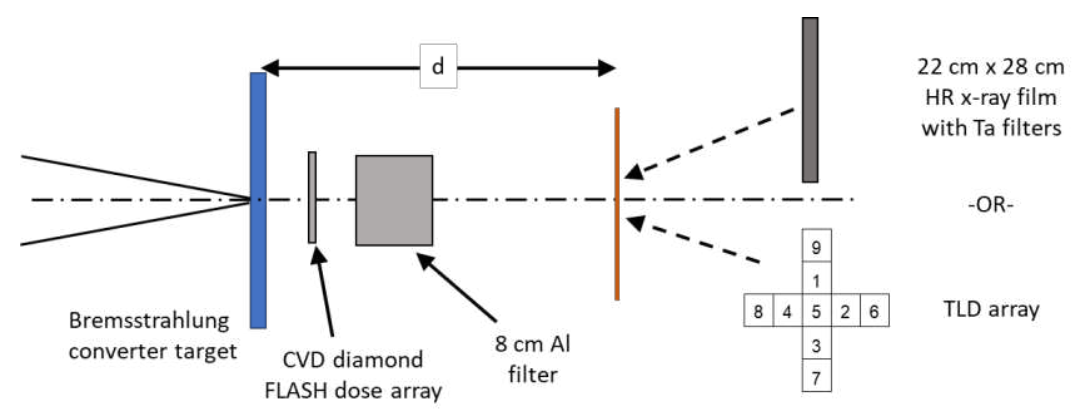


Collimated/Filtered Profile

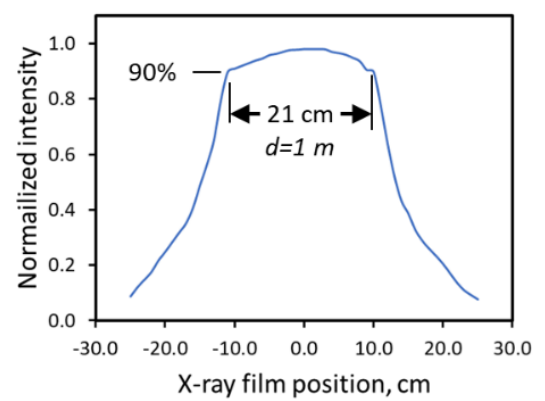

Integrated Dose, 70 ns pulse

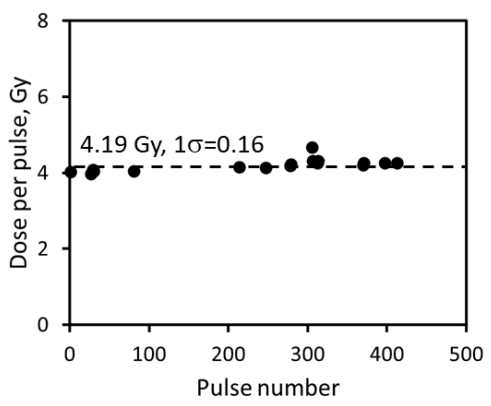

2

3 Figure 4 - Experiments stabilizing the bremsstrahlung pulse from the Flash X-ray (FXR) linear

4 induction accelerator. (a), (b) Depict a primary mechanism of spoiling the beam focus in a pulse;

5 ions created by the electron beam interaction create a plasma where the space charge of the

6 beam accelerates ions away from the target and partially neutralizes the beam. (c) Depicts a

7 method used to determine the surface and target contamination using Rutherford scattering

8 and secondary ion mass spectroscopy. (d) Plasma measurements were made to determine the

9 plasma expansion speed of both contaminants and target material. (e) Shows the dynamic

10

11

12

13

14

15 
a
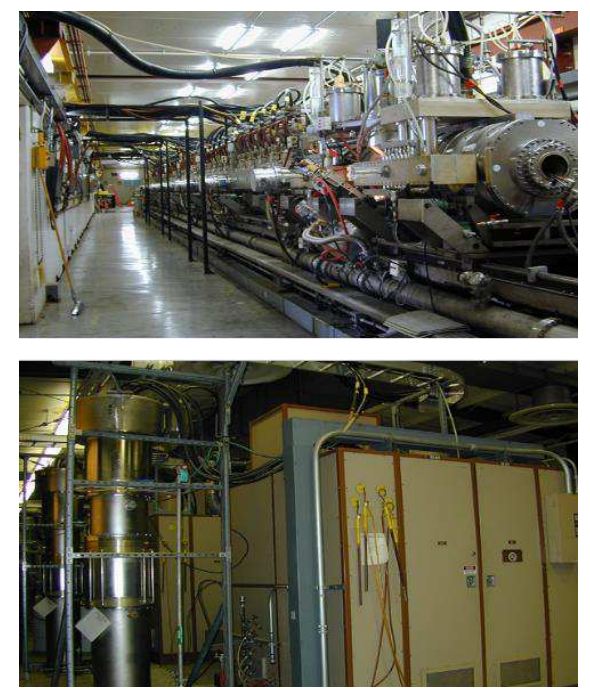

2

C

3

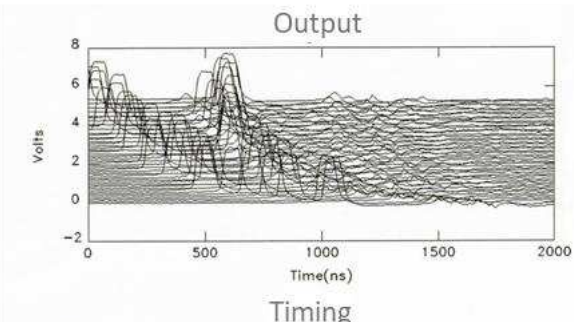

Fraction: 0.20000

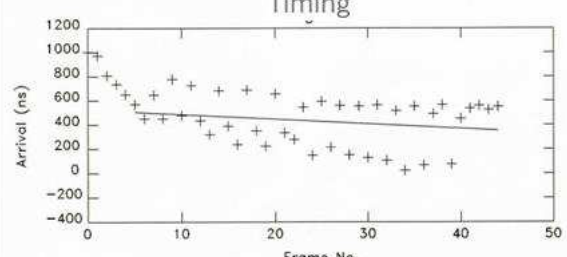

Mean (ns): $\quad 475.54$ Sdev (ns): $\quad 231.71$ N Good : $\quad 45$

Slope: $\quad-3.9155$ Intercept: 526.57

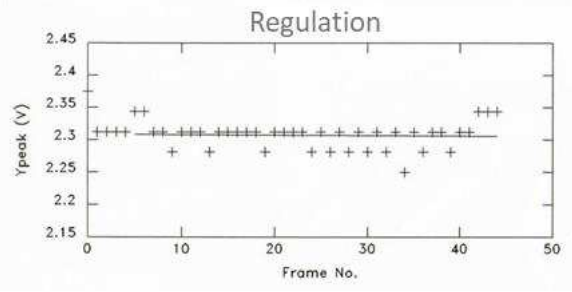

Mean (V): 2.3090 Sdev (V): $2.20863 \mathrm{E}-02$ N Good : $\quad \begin{array}{r}2.3091 \\ 45\end{array}$

Slope: $\quad-7.32880 E-05$ Intercept: 2.3088 b

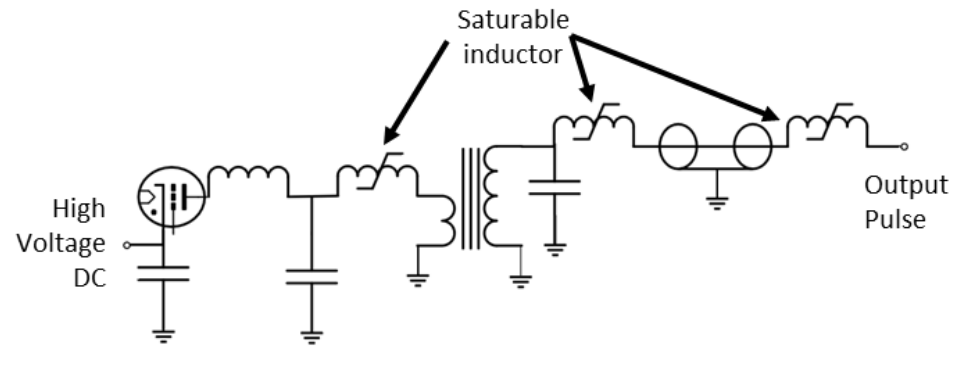

d
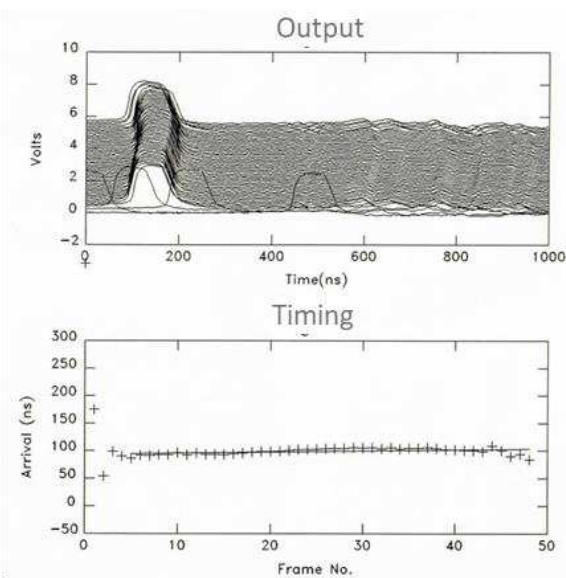

Mean (ns): $\quad 106.43$ Sdev (ns): $\quad 50.290$ N Good : $\quad \begin{array}{r}117.79 \\ 49\end{array}$

Slope: $\quad 0.19328$ Intercept: $\quad 93.857$
Deviafion: $\quad 5.2500$

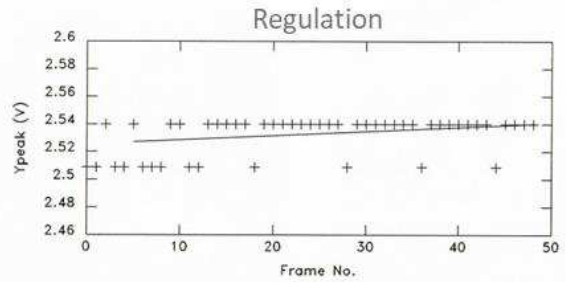

Mean (v): 2.5317 Sder (V): $1.36370 \mathrm{E}-02$ Rms (v): 2.5317

Slope: $\quad 3.01584 \varepsilon-04$ Intercept: 2.5256

4 
e

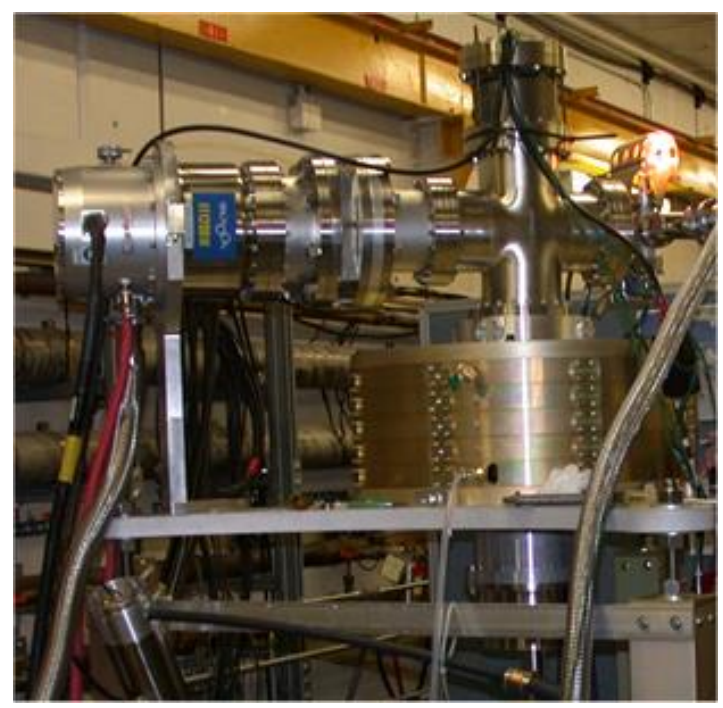

2

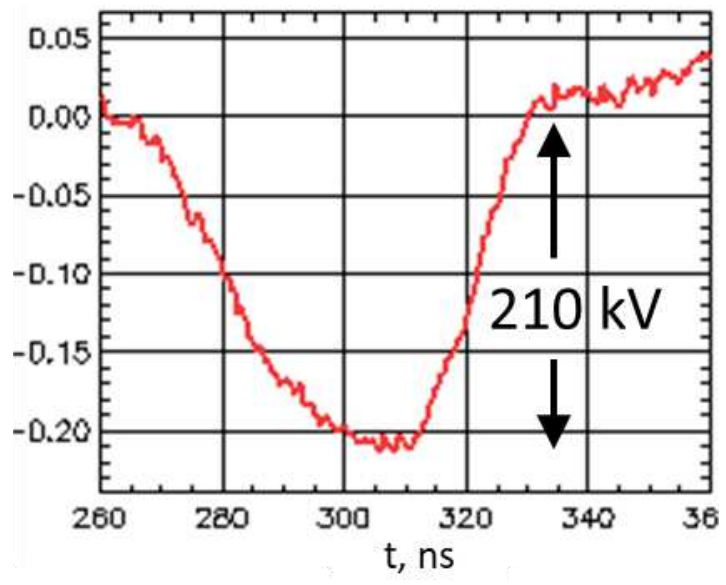

h

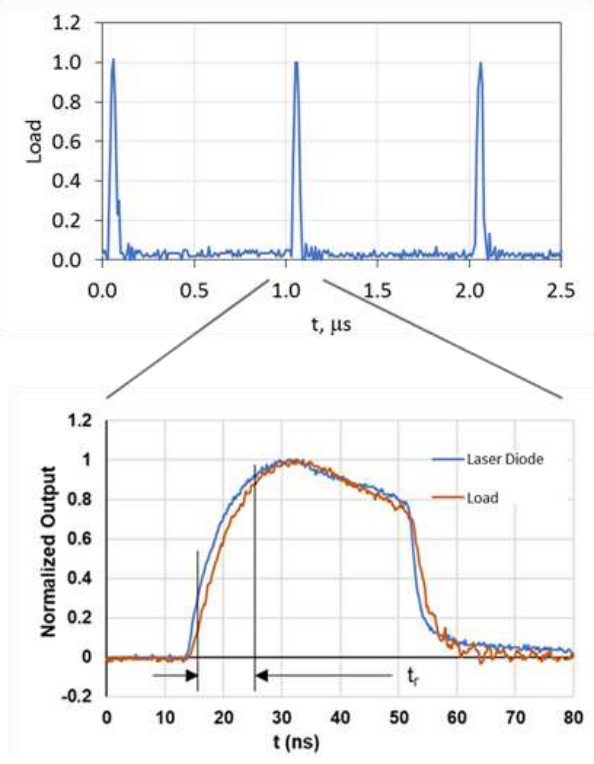

4

Figure 5 - Development of high repetition rate LIAs. (a) The Experimental Test Accelerator-II (ETA-II) at Lawrence Livermore National Laboratory nominally rated at 3000-A beam current,

$6 \quad 6.5 \mathrm{MeV}$, at $5 \mathrm{kHz}$ (top) and the pulsed sources using thyratron gas switches and a Melville 7 pulse compression transmission line (bottom). (b) Schematic of the pulsed source. (c) (d) Effect 8 of stabilizing the repeatability of the pulsed sources at $5000 \mathrm{~Hz}$. (e) (f) First tests on high 9 gradient cavities operating at $42 \mathrm{kV}$ per cell using $\mathrm{SF}_{6}$ insulation gas; we anticipate better than 10 twice the performance using oil insulation. (g) (h) Testing silicon carbide switching using the 11 optical transconductance varistor (OTV) technology 60. 
a

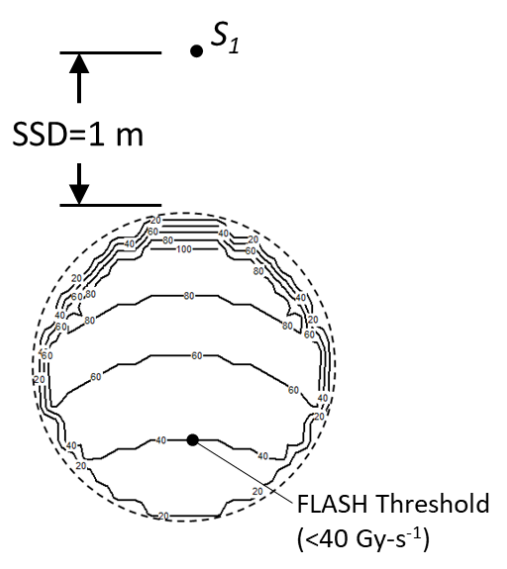

1

C

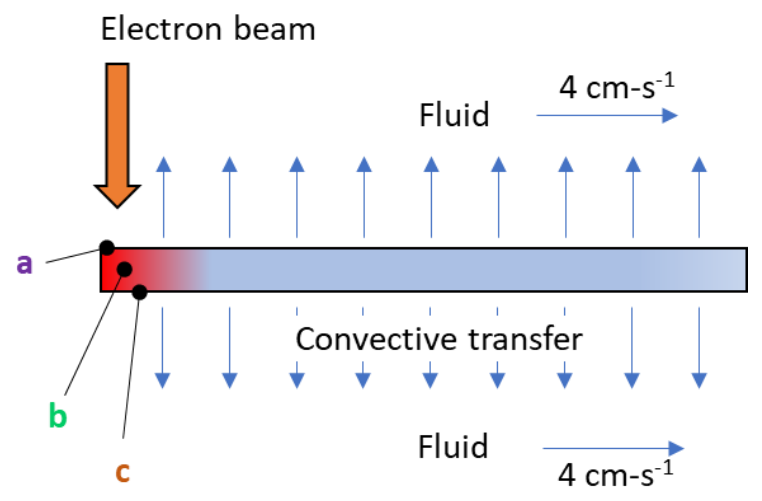

2

3 b

- $S_{1}$

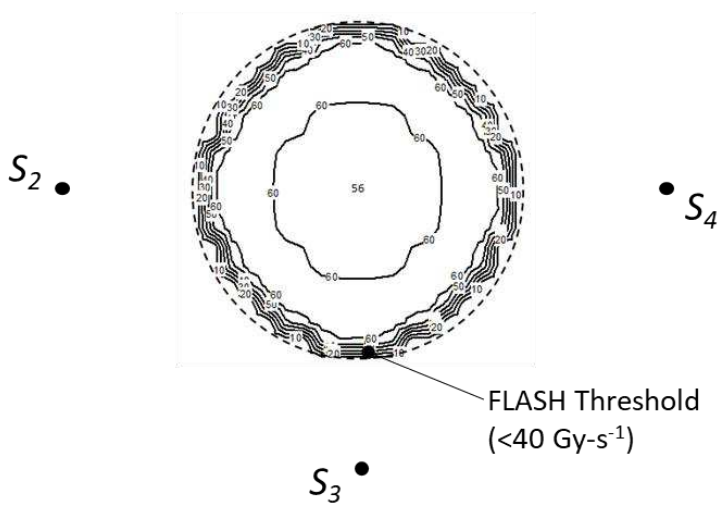

d

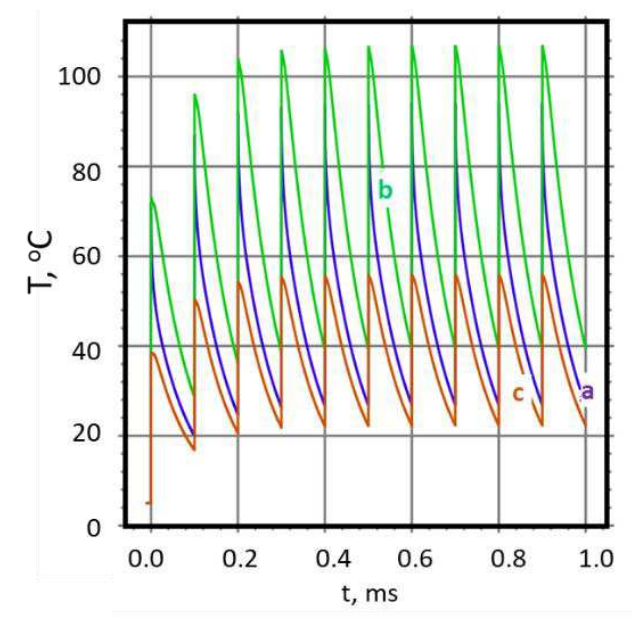

f

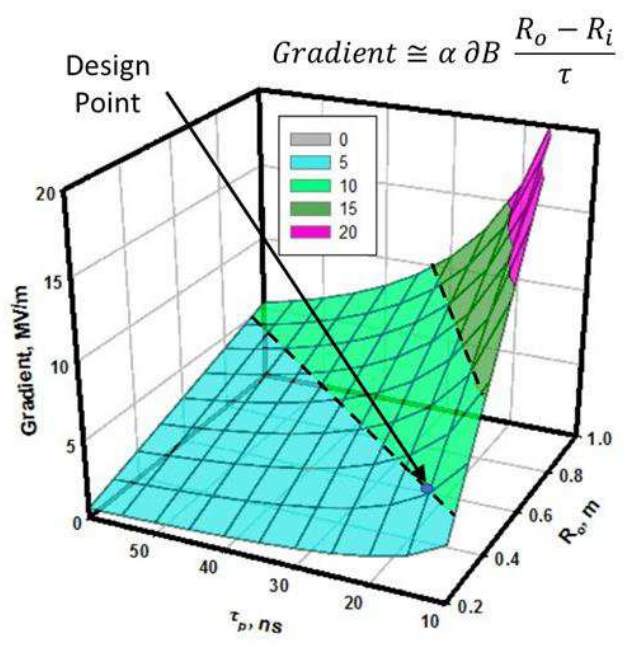




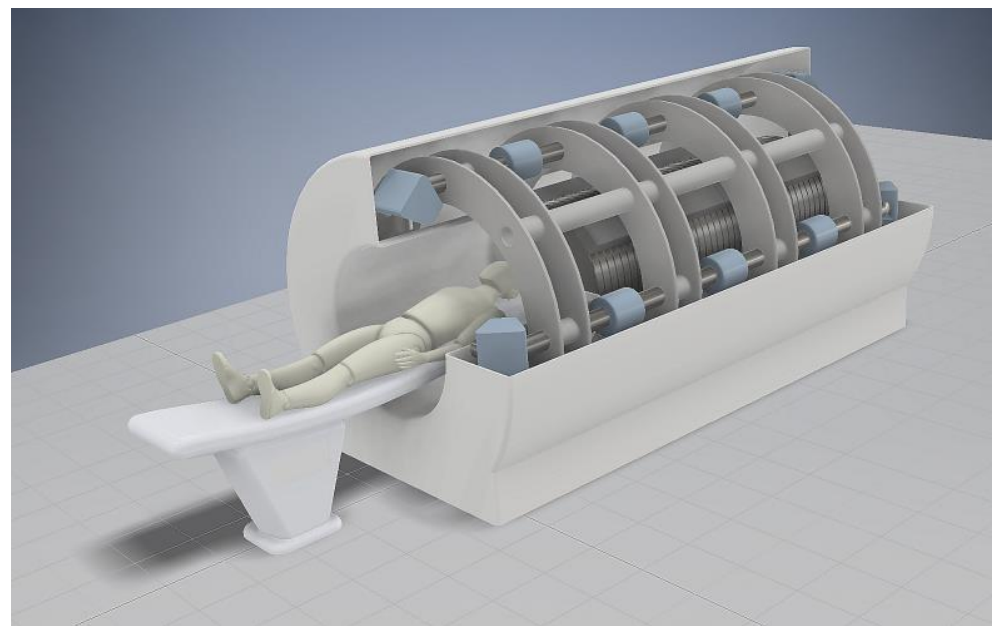

\begin{tabular}{|l|r|}
\hline \multicolumn{1}{|c|}{ Parameter } & $\begin{array}{c}\text { Induction } \\
\text { Linear } \\
\text { Accelerator }\end{array}$ \\
\hline Electron Energy (MeV) & 16 \\
Total Beam Current (A) & 25 \\
Pulse Width (s) & $1.50 \mathrm{E}-08$ \\
Pulse Repetition Frequency (Hz) & 10000 \\
Net Gradient (MeV/m) & 5.0 \\
Accelerator Length (m) & 3.20 \\
Inner Radius (cm) & 10.0 \\
\hline Instantaneous Surface Dose Rate (Gy/s) & $6.60 \mathrm{E}+05$ \\
Average Surface Dose Rate (Gy/s) & 98.9 \\
Total Dose (Gy) & 19.8 \\
Time On (s) & 0.20 \\
\hline
\end{tabular}

Figure 6 - Point design considerations for a high gradient linear induction accelerator for

2 FLASH-RT. (a) (b) $100 \mathrm{~Gy}-\mathrm{s}^{-1}$ single sources and four $25 \mathrm{~Gy}-\mathrm{s}^{-1}$ multisource dose rate calculations

3 to deliver above the tissue sparing threshold and reduced toxicity. Single source results in a

4 below tissue sparing dose at the exit edge whereas the four sources provide a nearly uniform

5 distribution above the $40 \mathrm{~Gy}-\mathrm{s}^{-1}$ heathy tissue sparing threshold. (c) (d) Cooled multilayer target

6 considerations. Multilayer target enables rapid cooling from the target interior causing the target temperature to equilibrate at approximately $110^{\circ} \mathrm{C}$. (e) (f) Induction cavity design based

8 on volt-second properties of the core and the dimensions, where: $\alpha$ - cavity packing efficiency,

$9 \partial \mathrm{B}$ - flux swing of the magnetic core, $\mathrm{R}_{\mathrm{i}}$ - core inner radius, $\mathrm{R}_{\circ}$ - core outer radius, and $\tau$ -

10 accelerator pulse width. For our design point, we take $R_{i}=0.1-m, \partial B \approx 0.6 T$ (NiZn ferrite), and $\alpha$

$11=60 \% 67$ 38. (g) Concept FLASH RT system using a linear induction accelerator (LIA) providing

12 four lines-of-sight. LIA is on axis with the patient. Blue elements are magnetic focusing

13 elements that direct the electron beam to the patient. Accelerator is $3.2 \mathrm{~m}$, overall system

14 length is $3.5 \mathrm{~m}$ less the patient couch. 
TABLE I - Present methods of FLASH-RT delivery

\begin{tabular}{|c|c|c|c|c|c|c|c|}
\hline \multirow{2}{*}{ Desig. } & \multirow{2}{*}{ System } & \multicolumn{2}{|c|}{ Technology } & \multirow{2}{*}{ Energy, MeV } & \multirow{2}{*}{$\begin{array}{c}\text { Average Dose } \\
\text { Rate, } \mathrm{Gy}-\mathrm{s}^{-1}\end{array}$} & \multirow{2}{*}{$\begin{array}{c}\text { Nominal } \\
\text { Area, } \\
\mathrm{cm}^{2}\end{array}$} & \multirow{2}{*}{ Reference } \\
\hline & & Type System & Scale & & & & \\
\hline \multicolumn{8}{|c|}{ Electrons } \\
\hline $\mathrm{a}$ & Oriatron (eRT6) & RF Linac & Clinical & $4.9-6$ & $1030-1080$ & 55.0 & Jaccard 2018 \\
\hline$b$ & Kinetron & RF Linac & Clinical & $4-5$ & 750 & 3.10 & Favaudon 2014 \\
\hline c & ELBEc & $\begin{array}{c}\text { Superconducting } \\
\text { RF Linac }\end{array}$ & $\begin{array}{l}\text { Large laboratory - } \\
\text { Helmholtz-Zentrum } \\
\text { Dresden-Rossendorf }\end{array}$ & $5-40$ & $0.86-4.5 \times 10^{6}$ & 0.79 & Karsch 2012 \\
\hline$d$ & Elekta Precise & RF Linac & Clinical & $\approx 8$ & 300 & 19.6 & Lempart 2019 \\
\hline $\mathrm{e}$ & Varian Clinac 21EX & RF Linac & Clinical & 9,20 & $35-210$ & 12.6 & Schüler 2017 \\
\hline \multicolumn{8}{|c|}{ Photons } \\
\hline$f$ & ESRF (ID17) & Synchrotron & $\begin{array}{c}\text { Large laboratory - } \\
\text { European Synchrotron } \\
\text { Radiation Facility }\end{array}$ & 0.105 & 14000 & 0.50 & Crosbie 2015 \\
\hline g & IMBL & Synchrotron & $\begin{array}{l}\text { Large laboratory - } \\
\text { Imaging and Medical } \\
\text { Beam-Line, Australian } \\
\text { Synchrotron }\end{array}$ & 0.94 & 4441 & 0.60 & Archer 2019 \\
\hline $\mathrm{h}$ & MXR 160/22 & X-ray tube & Clinical & 0.16 & 114 & 0.79 & $\begin{array}{l}\text { Bazalova-Carter 2019, } \\
\text { Esplen } 2019\end{array}$ \\
\hline \multicolumn{8}{|c|}{ Protons } \\
\hline $\mathrm{i}$ & Proteus IBA & $\begin{array}{l}\text { Superconducting } \\
\text { synchro-cyclotron }\end{array}$ & Specialized clinic & 230 & 39.1 & 0.79 & $\begin{array}{l}\text { Henrotin 2016, } \\
\text { de Walle } 2016\end{array}$ \\
\hline j & HyperScan Mevion & $\begin{array}{l}\text { Superconducting } \\
\text { synchro-cyclotron }\end{array}$ & Specialized clinic & 230 & 130 & 1.10 & $\begin{array}{l}\text { Zwart } 2016 \\
\text { Darafsheh } 2020\end{array}$ \\
\hline k & $\begin{array}{l}\text { ProBeam Varian } \\
\text { (Based on } \\
\text { publications) }\end{array}$ & $\begin{array}{l}\text { Superconducting } \\
\text { isochronous } \\
\text { cyclotron }\end{array}$ & Specialized clinic & 250 & 40.0 & 3.00 & $\begin{array}{l}\text { Abel 2019, } \\
\text { Girdhani 2020, } \\
\text { Darafsheh } 2020\end{array}$ \\
\hline 1 & $\begin{array}{c}\text { SNAKE } \\
\text { Experimental } \\
\text { (micro-beam) }\end{array}$ & $\begin{array}{c}\text { Tandem Van de } \\
\text { Graaff accelerator } \\
\text { using a beam } \\
\text { buncher }\end{array}$ & $\begin{array}{c}\text { Large Laboratory - Maier } \\
\text { Leibnitz-Laboratorium }\end{array}$ & 20 & $8.0 \times 10^{5}$ & $7.5 \times 10^{-5}$ & Dollinger 2009 \\
\hline
\end{tabular}




\begin{tabular}{|c|c|c|c|c|c|c|}
\hline Facility & Location & $\begin{array}{l}\text { Energy } \\
(\mathrm{MeV})\end{array}$ & $\begin{array}{c}\text { Beam } \\
\text { Current }(A)\end{array}$ & $\begin{array}{l}\text { Pulse } \\
\text { Width } \\
\text { (ns) }\end{array}$ & $\begin{array}{l}\text { Maxmium pulse } \\
\text { repetition rate }(\mathrm{Hz}) \\
{[\text { Total No. Pulses] }}\end{array}$ & Reference \\
\hline SLIA & $\begin{array}{c}\text { Pulse Science Incorporated, } \\
\text { USA }\end{array}$ & 5.5 & 10,000 & 30 & & Smith, 1997 \\
\hline Astron & $\begin{array}{c}\text { Lawrence Livermore National } \\
\text { Laboratory, USA }\end{array}$ & 6 & 800 & 300 & $1400[100]$ & Beal, 1969 \\
\hline ETA-II & $\begin{array}{c}\text { Lawrence Livermore National } \\
\text { Laboratory, USA }\end{array}$ & 6.5 & 3,000 & 50 & $5000[50]$ & Allen, 1993 \\
\hline ETIGO-III & Nagaoka University, Japan & 8 & 5,000 & 30 & 1 & Yatsui, 1996 \\
\hline PIVAR & $\begin{array}{c}\text { Centre d'études scientifiques } \\
\text { et techniques d'Aquitaine- } \\
\text { Cesta, France }\end{array}$ & 8 & 3,500 & 80 & 1 & Anthouard, 1996 \\
\hline SILUND-21 & $\begin{array}{l}\text { Joint Institute for Nuclear } \\
\text { Research-Dubna, Russia }\end{array}$ & 10 & 1,000 & 60 & & Fateev, 1995 \\
\hline LIAXF/LIAXFU & Institute of Fluid Physics, China & 12 & 2,600 & 90 & 1 & Deng, 1998 \\
\hline FXR & $\begin{array}{c}\text { Lawrence Livermore National } \\
\text { Laboratory, USA }\end{array}$ & 17 & 3,000 & 60 & 0.3 & Kulke, 1983 \\
\hline DARHT-II & $\begin{array}{l}\text { Los Alamos National } \\
\text { Laboratory, USA }\end{array}$ & 17 & 2,100 & 1,600 & 1 & Burns, 2001 \\
\hline DARHT-I & $\begin{array}{l}\text { Los Alamos National } \\
\text { Laboratory, USA }\end{array}$ & 20 & 2,000 & 60 & 1 & Burns, 1999 \\
\hline AIRIX & $\begin{array}{l}\text { Centre d'études scientifiques } \\
\text { et techniques d'Aquitaine- } \\
\text { Pontfaverger-Moronvilliers, } \\
\text { France }\end{array}$ & 20 & 4,000 & 80 & 1 & Merle, 1998 \\
\hline DRAGON-I & Institute of Fluid Physics, China & 20 & 3,000 & 90 & 1 & Deng, 2002 \\
\hline LIA 30/250 & $\begin{array}{l}\text { Joint Institute for Nuclear } \\
\text { Research-Dubna, Russia }\end{array}$ & 30 & 250 & 500 & 50 & Takayama, 2011 \\
\hline ATA & $\begin{array}{c}\text { Lawrence Livermore National } \\
\text { Laboratory, USA }\end{array}$ & 45 & 10,000 & 75 & $1000[10]$ & Reginato, 1983 \\
\hline
\end{tabular}




\section{Supplementary Information}

Acknowledgements - This work was performed under the auspices of the U.S. Department of Energy by Lawrence Livermore National Laboratory under Contract DE-AC52-07NA27344. Work performed by Opcondys, Inc. was funded separately by the United States government under ARPA-E (Contract No. DE-AR0000907), the National Science Foundation (Grant No. 1519964), and the California Energy Commission CalSEED Program (Grant No. 17-01-03). We acknowledge Isik C. Kizilyalli, Eric Carlson, and Danny W. Cunningham for their guidance and encouragement of the high voltage switch work and especially the help of lan D. Smith for his reading and key insights into the development of this manuscript. We especially wish to thank the FXR and ETAIl experimental staff, specifically Alan Hill and Blake Kreitzer.

Author Contributions - SES was the principal author and developed the overall approach for the system and conducted the initial bremsstrahlung target experiments. KCS conducted and led the photoconductive switch experiments, developed the thermal models for the high-power target, and analytical expression for the dose profile from multiple sources. GJC and YJC developed the LIA concepts and beam transport approaches. In addition, YCJ developed the optimized focusing approaches and led the physics theoretical work associated with the beam target interaction. SF developed and built the $\mathrm{x}$-ray pinhole camera and took the gated images of the target spot behavior. SAH developed the concept along with the guidance of JH. In addition, $\mathrm{JH}$ provided the oncology expertise for the paper. JAW developed pulse and regulation stabilization algorithms and approaches for the $5 \mathrm{kHz}$ pulsed sources. JMZ conducted the FXR stability experiments and FLASH detector calibrations.

Competing Interests Statement - This paper is a result of Federally sponsored research or development. The United States Government has rights to patents pursuant to Contract No. DE-AC52-07NA27344 between the United States Department of Energy and Lawrence Livermore National Security, LLC for the operation of Lawrence Livermore National Laboratory. Opcondys, Inc. is a for profit company and may profit from the technologies described in this paper.

Disclaimer - Reference herein to any specific commercial products, process, or service by trade name, trademark, manufacturer, or otherwise, does not necessarily constitute or imply its endorsement, recommendation, or favoring by the U.S. government or Lawrence Livermore National Security, LLC. The views and opinions of authors expressed herein do not necessarily state or reflect those of the U.S. government or Lawrence Livermore National Security, LLC, and shall not be used for advertising or product endorsement purposes. 
Figures
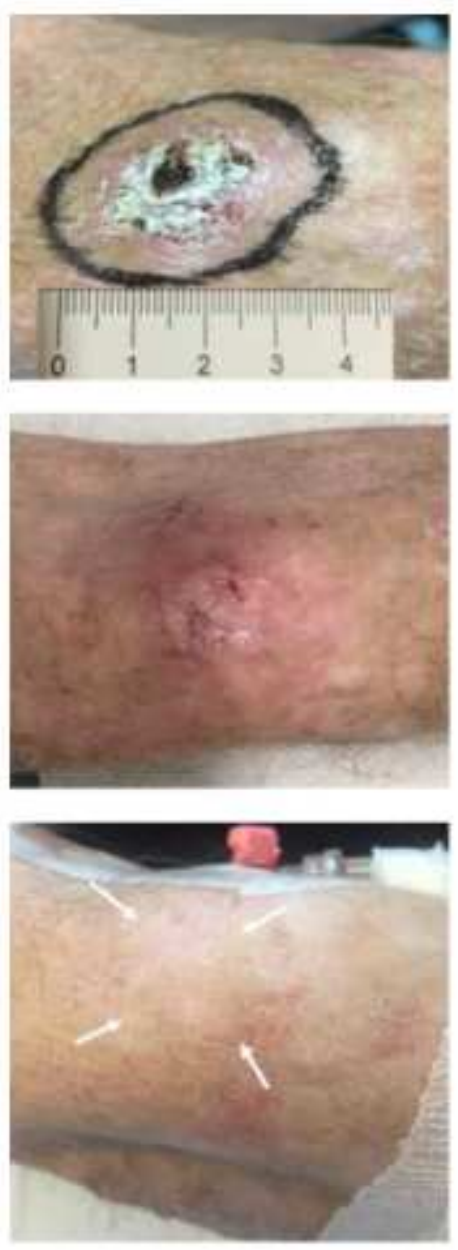

\section{Figure 1}

Effects of $167 \mathrm{GY} / \mathrm{s}$ (15-Gy in 90-ms) electron beam treatment of a 3.5-cm skin tumor in the first FLASHRT of a human subject. Top: Day 0, middle: Day 21, bottom: Day 150 [ 8] (Reprinted with permission, License No. 5054930939964). 


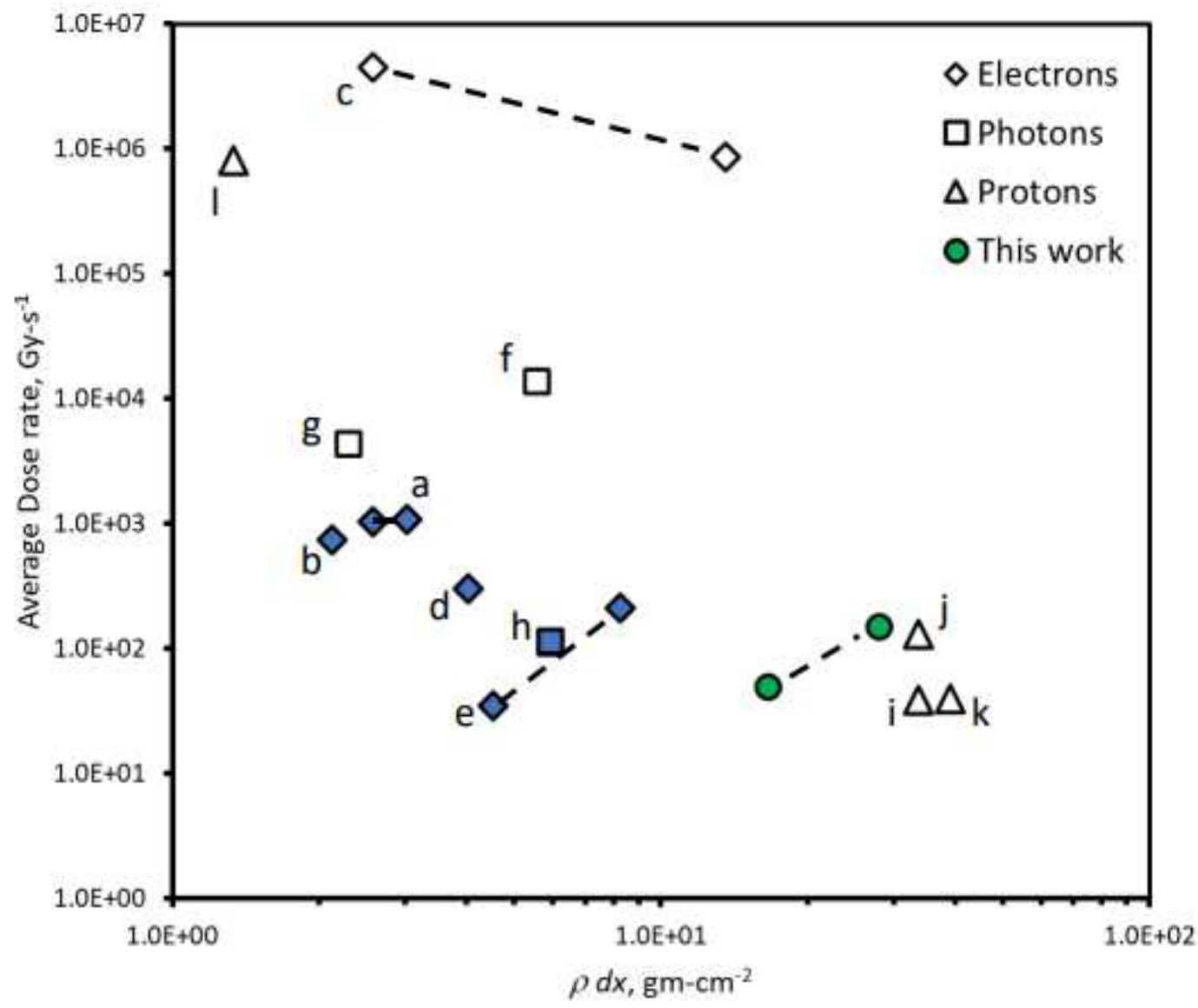

Figure 2

A survey of FLASH-RT average dose rate as a function of range calculated from details obtained from the literature. See Table I for specific details. Solid blue markers designate clinic scale systems that can be placed in approximately a $100 \mathrm{~m} 3$ radiation vault. Dotted line signifies the approximate range of a particular single system.

$$
U=q \oint \boldsymbol{E} \cdot d \boldsymbol{l}
$$

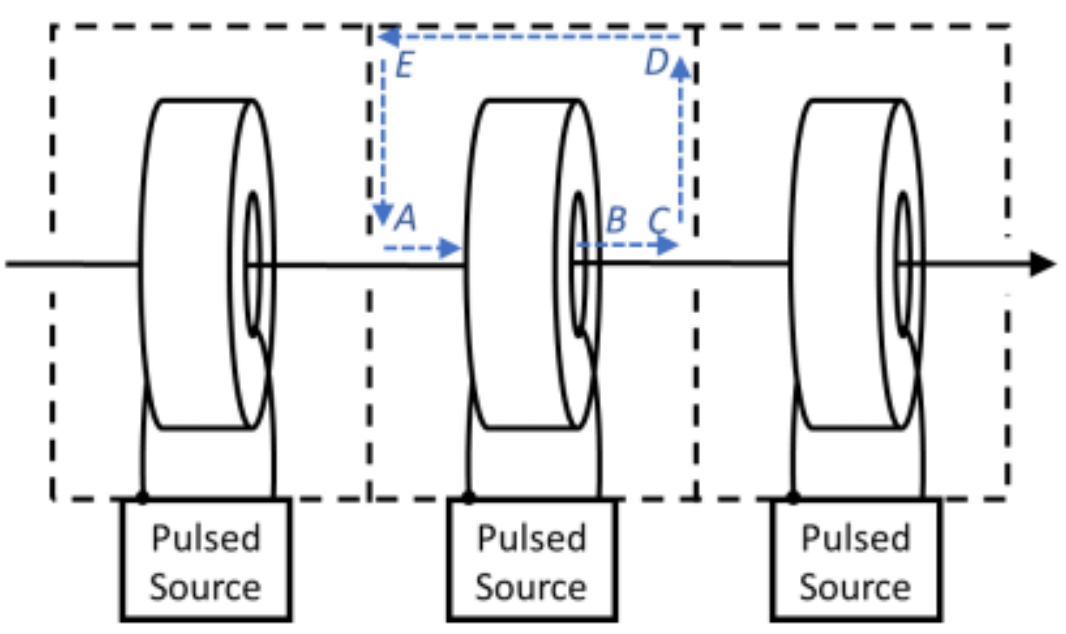


Figure 3

Acceleration of charged particles (on axis arrow) with a linear induction accelerator (LIA).

a

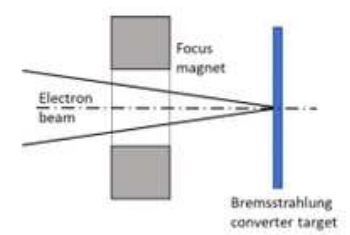

c

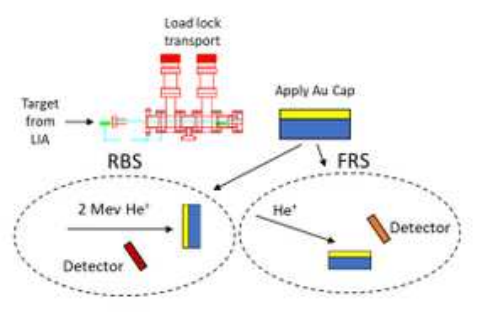

b

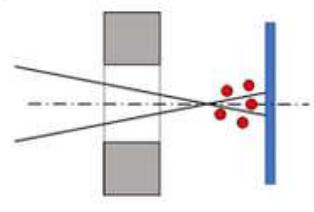

d
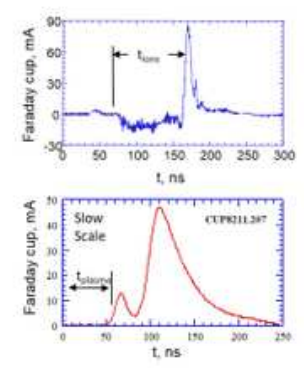

e

\begin{tabular}{|c|c|}
\hline (13) & 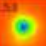 \\
\hline ( & $\theta$ \\
\hline 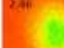 & $\theta$ \\
\hline $8 \pi$ & + \\
\hline
\end{tabular}

f

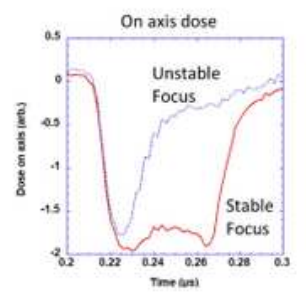

g

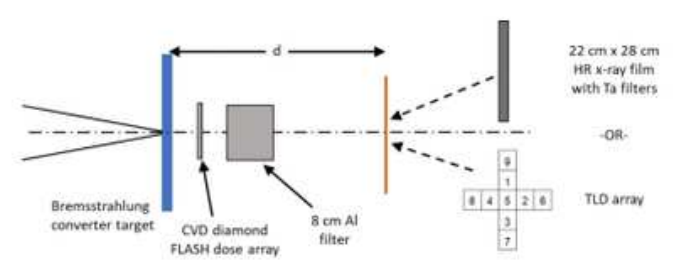

h

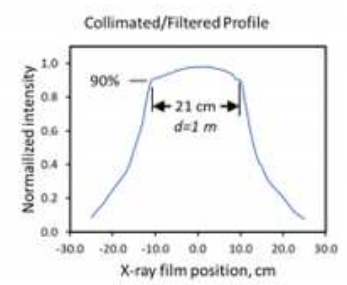

i

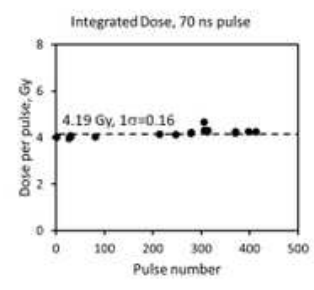

\section{Figure 4}

Experiments stabilizing the bremsstrahlung pulse from the Flash X-ray (FXR) linear induction accelerator. 
a
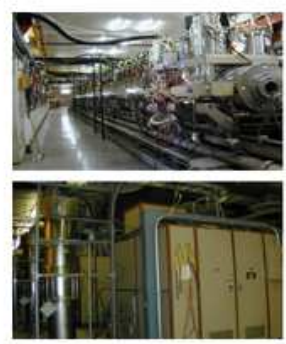

c

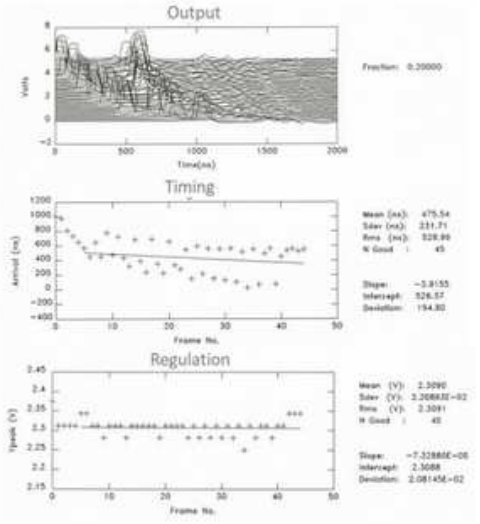

e
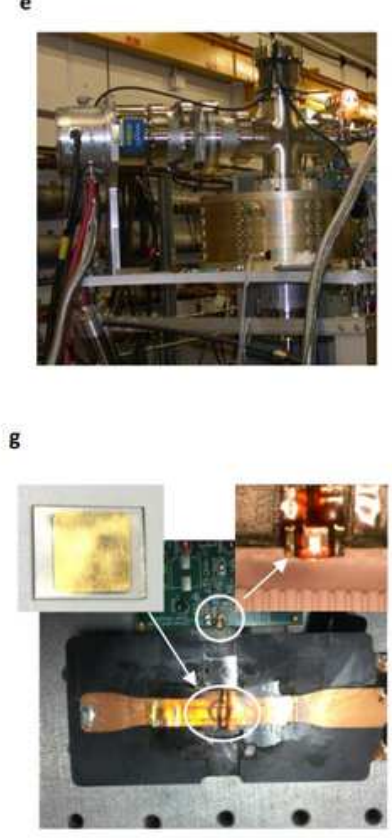

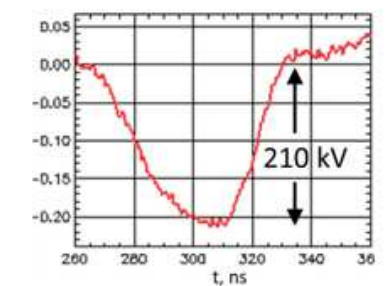

b
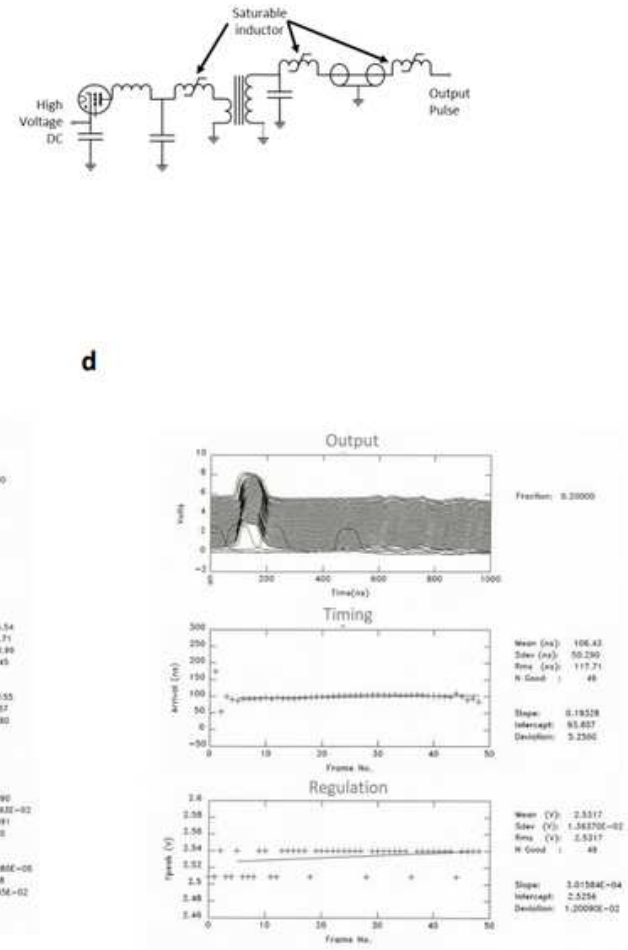

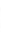

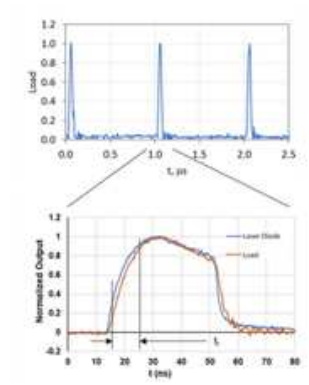

Figure 5

Development of high repetition rate LIAs. 
a

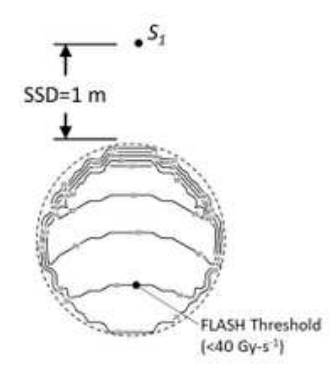

c

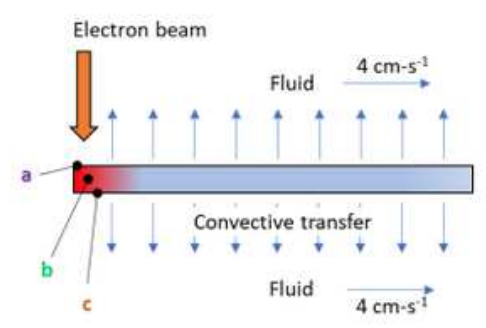

e

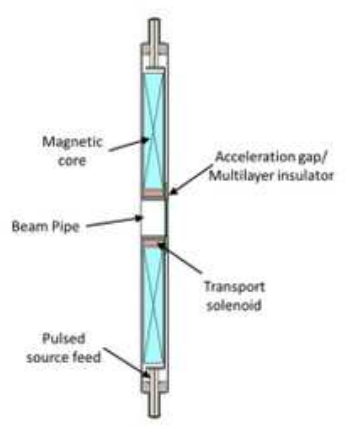

\section{g}

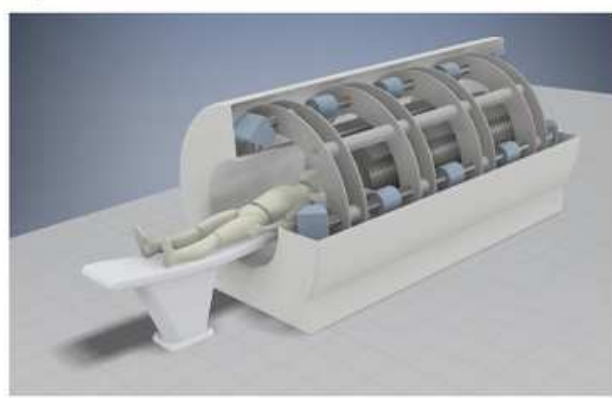

b

- $S_{1}$

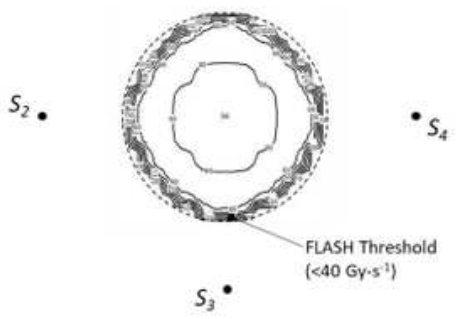

d

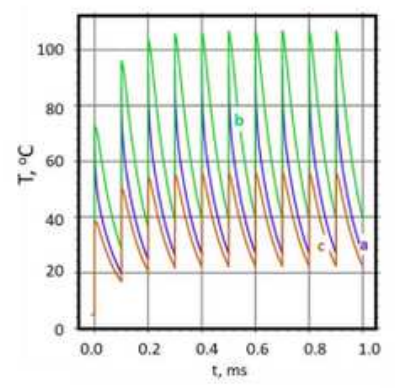

f

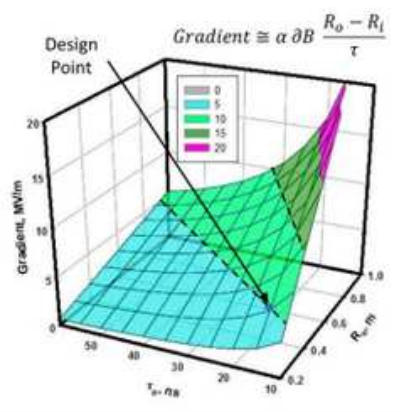

\begin{tabular}{|l|r|}
\hline \multicolumn{1}{|c|}{ Parameter } & $\begin{array}{c}\text { Induction } \\
\text { Linear } \\
\text { Accelerator }\end{array}$ \\
\hline \hline Electron Energy (MeV) & 16 \\
Total Beam Current (A) & 25 \\
Pulse Width (s) & $1.50 E-08$ \\
Pulse Repetition Frequency (Hz) & 10000 \\
Net Gradient (MeV/m) & 5.0 \\
Accelerator Length (m) & 3.20 \\
inner Radius (cm) & 10.0 \\
\hline Instantaneous Surface Dose Rate (Gy/s) & $6.60 \mathrm{E}+05$ \\
Average Surface Dose Rate (Gy/s) & 98.9 \\
Total Dose (Gy) & 19.8 \\
Time On (s) & 0.20 \\
\hline
\end{tabular}

\section{Figure 6}

Point design considerations for a high gradient linear induction accelerator for FLASH-RT. 